\title{
$1 \quad$ PAX8 orchestrates an angiogenic program through interaction with SOX17
}

3 Daniele Chaves-Moreira ${ }^{1}$, Marilyn A. Mitchell ${ }^{1}$, Cristina Arruza ${ }^{1}$, Priyanka Rawat ${ }^{1}$, Simone Sidoli ${ }^{2,3}$, 4 Robbin Nameki ${ }^{4,5}$, Jessica Reddy ${ }^{4,5}$, Rosario I. Corona ${ }^{4,5}$, Sisi Ma ${ }^{6}$, Boris Winterhoff ${ }^{7}$, Gottfried E. 5 Konecny $^{8}$, Benjamin A. Garcia², Donita C. Brady ${ }^{9,10}$, Kate Lawrenson ${ }^{4,11}$, Patrice J. Morin ${ }^{1}$ and Ronny 6 Drapkin $^{1^{*}}$.

${ }^{1}$ Ovarian Cancer Research Center, Department of Obstetrics and Gynecology, University of Pennsylvania Perelman School of Medicine. Biomedical Research Building II/III, Suite 1224, Philadelphia, PA, USA.

10 'Epigenetics Institute, Department of Biochemistry and Biophysics, Smilow Center for Translational Research, University of 11 Pennsylvania Perelman School of Medicine, Suite 9-124, Philadelphia, PA, USA.

12 '3Current affiliation: Department of Biochemistry, Albert Einstein College of Medicine, Bronx, NY, USA.

13 "Women's Cancer Program at the Samuel Oschin Comprehensive Cancer Center, Cedars-Sinai Medical Center, Los 14 Angeles, CA, USA.

$15{ }^{5}$ Division of Gynecologic Oncology, Department of Obstetrics and Gynecology, Cedars-Sinai Medical Center, Los Angeles, 16 CA, USA.

$17{ }^{6}$ Institute for Health Informatics, University of Minnesota, MN, USA.

18 'Department of Obstetrics, Gynecology and Women's Health, Division of Gynecologic Oncology, University of Minnesota, 19 Minneapolis, MN, USA.

$20 \quad{ }^{8}$ Department of Medicine, David Geffen School of Medicine, University of California Los Angeles, Los Angeles, CA. USA.

21 'Department of Cancer Biology, University of Pennsylvania Perelman School of Medicine. Biomedical Research Building 22 II/III, Suite 612, Philadelphia, PA, USA.

$23{ }^{10}$ Abramson Family Cancer Research Institute, University of Pennsylvania Perelman School of Medicine. Biomedical 24 Research Building II/III, Suite 612, Philadelphia, PA, USA.

*Correspondence: rdrapkin@pennmedicine.upenn.edu

29 Keywords: PAX8, SOX17, SERPINE1, Transcription factor, Gene regulation, Ovarian Cancer, 30 Fallopian tube, Tumor angiogenesis. 


\section{ABSTRACT}

Worldwide, the number of new ovarian cancer cases approaches 300,000 with more than 33180,000 deaths every year. The low survival-rate reflects the limitations of current therapies and 34 highlights the importance of identifying new therapeutic targets. Despite significant recent efforts to 35 identify novel vulnerabilities in ovarian cancer, none have led to effective durable therapies with 36 improvement in overall survival. PAX8, a lineage-transcription factor, whose expression is a major 37 molecular feature of ovarian carcinomas, represents a novel therapeutic target. Herein, we have 38 identified SOX17 as a bona fide PAX8-interacting partner and elucidated the impact of this interaction on the development of ovarian cancer. Importantly, we found that PAX8 and SOX17 regulate tumor 40 angiogenesis in vitro and in vivo. The role of PAX8 and SOX17 in the regulation of angiogenesis reveals

41 a novel function for these factors in regulating the tumor microenvironment and highlight this pathway as a viable therapeutic target. 


\section{INTRODUCTION}

Epithelial ovarian carcinoma is the most lethal of all gynecologic malignancies, claiming an estimated 14,000 lives annually in the United States of America (1) with worldwide numbers approaching 180,000 deaths annually (2). The lack of effective screening tools result in the majority of cases being diagnosed at an advanced stage and thus translating into a 5-year survival rate of less than $30 \%$ (3). The absence of adequate screening is compounded by the propensity of this disease to acquire chemoresistance and relapse of disease in the majority of patients despite initial response to platinum-based chemotherapy and surgical cytoreduction. Although much progress in ovarian cancer disease knowledge has emerged, effective targeted therapies have yet to impact overall survival rates (4).

The knowledge of the pathogenesis of high-grade serous ovarian carcinoma (HGSOC), the most common subtype of this disease, has greatly advanced over the past decade. A number of studies support the fallopian tube secretory epithelial cells (FTSEC) as the site of origin of the majority of HGSOC (5-13). The development of female reproductive tract is governed by the PAX8 transcription factor (14), which is a member of the Paired-Box family of transcription factors that play essential roles during embryogenesis and tumorigenesis (15). In normal oviducts, PAX8 expression is restricted to the secretory cells while neighboring ciliated cells show no expression. The sustained expression of PAX8 in the adult FTSEC and in nearly all HGSOCs (16), previously led us to use the PAX8 promoter to develop a genetically engineered mouse model of $\operatorname{HGSOC}(17,18)$. Knockdown of PAX8 in ovarian cancer cells leads to apoptosis (19-21) supporting a definitive role for PAX8 in ovarian cancer growth and progression. However, it remains unclear how PAX8 drives the development of the Mullerian reproductive tract or how it supports neoplastic growth.

Surprisingly, PAX8 knockdown following transcriptome analysis revealed a negligible impact on the FTSEC cell lines with very few transcripts significantly affected by PAX8 loss $(21,22)$. In contrast, the range of transcripts altered by PAX8 loss in cancer cell lines was considerably higher. Ontology 
analysis of the alterations after PAX8 loss showed changes in proliferation, angiogenesis and adhesion

pathways that are crucial for tumor progression (22). Chromatin immunoprecipitation-sequencing

(ChIP-seq analysis) showed that the PAX8 cistrome is reprogrammed during the process of malignant

71 transformation by the widespread redistribution of PAX8 binding sites in the genome of ovarian cancer

cells. Moreover, a recent study showed that non-coding somatic mutations disrupt the PAX8

transcriptional program in ovarian cancer (23).

To further survey the roles of PAX8 in ovarian carcinomas, we purified the PAX8 protein complex

75 from a panel of different fallopian tube secretory cells, and different ovarian carcinoma cells and

76 identified its components. Our analyses reveal that PAX8 is part of a NuRD chromatin remodeling complex and associates with multiple factors including SOX17. We show that depletion of PAX8 or SOX17 impacts the expression of factors involved in angiogenesis and functionally disrupts capillary

79 formation in vitro and in mouse models. Disruption in angiogenesis greatly decreased tumor burden, 80 ascites formation and lead to improved survival. These findings support a role of PAX8 and SOX17 in 81 the regulation of angiogenesis and highlight this pathway as a viable therapeutic target. 


\section{RESULTS}

\section{Biochemical purification of the PAX8 complex}

To better understand the function of PAX8 in benign compared to malignant fallopian tube secretory cells, we developed a biochemical affinity-purification method (Figure 1A). First, we generated nuclear extracts as previously described (24) and purified the endogenous PAX8 protein complex from three ovarian carcinoma cell lines (OVCAR4, KURAMOCHI, and OVSAHO) and three immortalized fallopian tube secretory cell lines (FT194, FT246, and FT282) using anti-PAX8-specific antibodies. Immunoblotting following affinity chromatography demonstrated the specific enrichment of PAX8 in our system (Figure 1B). When the affinity-purified PAX8 complex was evaluated on sizeexclusion chromatography it revealed a size of approximately $600 \mathrm{kDa}$ (Figure 1C). Mass spectrometry analysis of the PAX8-containing fractions identified a number of putative PAX8-interacting proteins (Figure 1D and Table 1).

Remarkably, many of the putative PAX8-interacting proteins represent components of chromatin-remodeling complexes. For example, chromodomain-helicase-DNA-binding protein 4 (CHD4), Transcriptional repressor p66-alpha (GATAD2A), Metastasis-associated protein 2 (MTA2), histone deacetylases 1 (HDAC1) and Retinoblastoma binding protein 4 (RBBP4) are components of the nucleosome remodeling and deacetylase (NuRD) complex. The NuRD complex is responsible for transcriptional repression through histone deacetylation and nucleosome remodeling (25). Coincidently, NuRD complex core members, as the helicase CHD4, was also found to be an interactor and epigenetic coregulator of PAX3-FOXO1 in alveolar rhabdomyosarcoma (26).

To prioritize the putative PAX8-interacting partners for further study, we ranked the peptides by confident identification score (i.e. MaxQuant score), correlation with PAX8 expression in ovarian tumor tissues, and co-dependency in ovarian carcinoma cell lines. SOX17, a member of the Sry-related HMG box transcription factors family, exhibited the strongest correlation, co-dependency with PAX8 in ovarian cancer, and was identified among the top-ranked most abundant putative PAX8-interacting 
07 partners (Table 1 and SI 1). We confirmed SOX17 as a bona fide PAX8-interacting partner by showing

co-immunoprecipitation using agarose beads covalently bound to either a specific anti-PAX8 or antiSOX17 antibody, compared to rabbit IgG control beads (Figure 1E), indicating that PAX8 and SOX17 physically interact. Consistent with this finding, we observed co-elution of PAX8 and SOX17 in the same large molecular size fractions (Figure 1F), indicating that they are part of the same complex. We did not observe monomeric PAX8 or SOX17 in lower molecular weight fractions.

\section{PAX8 physically interacts with SOX17 in high-grade serous ovarian carcinoma}

We next characterized the location and levels of expression of PAX8 and SOX17 in five normal

human fallopian tube tissues compared to five different HGSOC cases by immunohistochemistry. As

shown in Figure 2A, we observed the co-expression of PAX8 and SOX17 restricted to the FT secretory

epithelial cells. We also observed the over-expression of both PAX8 and SOX17 in all HGSOC cases

(Figure 2A). Interestingly, PAX8 and SOX17 gene expression levels are significantly higher in ovarian

cancers and in benign fallopian tubes than normal ovaries (SI 2A-2B-2C).

Our immunohistochemical findings are supported by high-resolution immunofluorescence analyses showing the nuclear co-localization of PAX8 and SOX17 in three different immortalized

fallopian tube secretory cell lines (FT194, FT246, and FT282) and three high-grade serous ovarian carcinoma cell lines (OVCAR4, KURAMOCHI, and OVSAHO) (Figure 2B). To confirm the PAX8SOX17 physical interaction, we performed an in situ proximity ligation assay (PLA), which allows the identification of both stable and transient interactions at native protein levels. We confirmed increased interaction between PAX8 and SOX17 in all tested high-grade serous cells: OVCAR4, KURAMOCHI, and OVSAHO (Figure 2C and SI 2D). As expected for transcription factors, the observed protein-protein interactions were nuclei localized. Moreover, we further explored the PAX8-SOX17 interaction in five different HGSOC tissue samples and again we observed a stronger and higher number of PLA signals in the cancer samples than in the normal fallopian tube samples (Figure 2D), confirming that the PAX8- 
SOX17 interaction may be important in the process of malignant transformation. Moreover, in the

normal fallopian tube cases, the PLA signals (PAX8-SOX17 interaction) were restricted to the secretory cells, reinforcing the hypothesis that these cells are the site of origin for HGSOC.

\section{PAX8 and SOX17 are transcription co-regulators}

To assess whether SOX17 and PAX8 could mutually regulate each other, we used RNA

interference to knockdown each gene individually. After PAX8 knockdown, SOX17 protein levels were significantly reduced, in all tested FTSEC and HGSOC cell lines, and actually became undetectable in some lines (Figure 3A-3B and SI 3). Conversely, SOX17 knockdown also led to a decrease in the PAX8 protein level, but the effects were much less pronounced. At the RNA level, PAX8 loss led to a significant decline of SOX17 expression in all cell lines studied (Figure 3C) and SOX17 knockdown similarly led to a decrease of PAX8 expression (Figure 3D). These data suggest that SOX17 and PAX8 can transcriptionally regulate each other's mRNA expression and that, in the absence of PAX8, SOX17 protein is rapidly depleted.

Since the PAX8-SOX17 complex appears to transcriptionally regulate the PAX8 and SOX17 promoters, we performed luciferase reporter assay to directly test the transcriptional effect of this complex on minimal promoters containing five times PAX8 binding sites (27). Consistent with the results described above, knockdown of either PAX8 or SOX17 demonstrated a significant decline of luciferase activity mediated by PAX8-binding sites (Figure 3E-3F).

\section{PAX8 and SOX17 regulate a common set of genes}

To determine which pathways are regulated by the PAX8-SOX17 complex, we first performed RNA-seq following depletion of each factor individually, and in combination (siDUAL). Control cells received a non-targeting siRNA control pool (siNT). The efficiency of the knockdowns was assessed both by the number of sequenced reads, and Western blot $(\mathrm{SI} 3)$. Unsupervised analysis of the 
significantly altered transcripts after the loss of PAX8, SOX17, or both together is shown in Figure 4A

and Table 2. PAX8 and SOX17 can both negatively and positively regulate gene expression. PAX8

target genes were significantly more likely to be regulated by SOX17 than expected by chance ( $p$ $<0.00001$, Chi-squared test). Treatment with siRNAs to simultaneously deplete both factors largely phenocopied the maximal effect of either siPAX8 or siSOX17 (Figure 4A). We focused on the 380

62

genes that were commonly up-regulated (Figure 4B) under all three conditions. These genes were enriched in pathways associated with cell adhesion, blood vessel development, and angiogenesis (Figure 4C).

In order to further characterize the gene regulation coordinated by PAX8/SOX17, we performed targeted functional proteomic profiling using reverse-phase protein arrays (RPPA)s. Knockdown of PAX8, SOX17 or both resulted in significant changes across 142 proteins (Figure 4D and Table 3). Consistent with our observations made using RNA-seq, ontology analysis of the identified target genes showed that cell adhesion, and angiogenesis were among the pathways most significantly altered after PAX8 and/or SOX17 loss (SI 4C). When examining individual genes, we found that Serpin Family E Member 1 (SERPINE1), also called Plasminogen Activator Inhibitor 1 (PAI1), was the most highly elevated protein following knockdowns (Figure 4E). The protein data corroborate the RNA-seq analysis which also found SERPINE1 mRNA levels the most commonly up-regulated (SI 4A-4B). Interestingly, this gene has been implicated as an inhibitor of the tissue-type plasminogen activator and angiogenesis (28). Using immunoblotting and quantitative-PCR, we confirmed that PAX8 or SOX17 knockdown significantly increased the expression of SERPINE1 and all tested cells (Figure 4F-4G). Moreover, SERPINE1 presented a strong differential expression pattern between benign and malignant cells. All FTSEC lines exhibited higher levels of SERPINE1 compared to isogenic oncogene-transformed lines or ovarian cancer cell lines (SI 4D) and this expression was inversely correlated with the levels of PAX8/SOX17 (SI 4E). This suggests an important role for PAX8-SOX17-mediated SERPINE1 suppression in malignant transformation. 
82 SERPINE1 participates in PAX8-SOX17-mediated angiogenesis

Using an angiogenesis antibody array, we further examined the levels of 35 different secreted angiogenesis mediators in a panel of human ovarian carcinoma cells (OVCAR3, OVCAR4, 85 KURAMOCHI, and OVTOKO) and a panel of human fallopian tube secretory cells (FT33, FT194, FT246, and FT282). The FTSEC line-conditioned media exhibited a higher concentration of the

angiogenesis inhibitors such as SERPINE1 and THBS1, while the ovarian cancer lines secreted more angiogenesis inducers such as VEGFA, CXCL8, and CXCL16 (Figure 5A and SI 5). We found that some angiogenic factors were regulated by PAX8 and SOX17. Indeed, VEGFA, CXCL8, and CXCL16 exhibited reduction after the knockdown of PAX8 or SOX17 in the cancer lines, while their secretion in the normal lines was not detected (Figure 5B). However, the most prominent effect observed in cancer cell lines was a large increase in SERPINE1 secretion following PAX8 knockdown. SERPINE1 is particularly interesting because its secretion levels were also elevated in FTSECs compared to ovarian cancer lines. Indeed, FTSEC-conditioned media presented an average of $20 \mathrm{ng} / \mathrm{mL}$ of SERPINE1, which was many times higher than the secretion from ovarian cancer lines, an average of $0.2 \mathrm{ng} / \mathrm{mL}$ (Figure 5C-5D). Corroborating our previous findings, the secretion of SERPINE1 was significantly increased in HGSOC conditioned media following PAX8 or SOX17 knockdown (Figure 5E-5F).

\section{Roles of SERPINE1 and its regulators, PAX8 and SOX17, on ovarian tumor angiogenesis.}

Using the human umbilical vein endothelial cells (HUVEC) tube-formation assay, we found that conditioned media from ovarian carcinoma cells induced the formation of blood vessels in vitro, although not to the same extent as recombinant VEGF. This effect was almost abolished in conditioned media from ovarian cancer lines with PAX8 or SOX17 knockdown (Figure 6A). However, no induction of HUVECs tube formation was observed with the FTSEC lines conditioned media, which exhibit a higher concentration of SERPINE1 (Figure 6A-6B). We further investigated the VEGFR2 pathway status and corroborated the inactivation of the downstream effectors PLCy1 and ERK1/2 in endothelial 
07 cells exposed to HGSOC conditioned media after the loss of PAX8 or SOX17 when compared with the 08 no-targeting control knockdown (SI 6).

To extend these findings to an in vivo system, we performed in nude mice the directed in vivo angiogenesis assay (DIVAA) $(29,30)$. The DIVAA assay uses semi-closed small silicone cylinders

known as angioreactors. The cylinders can be filled with angiogenic or antiangiogenic compounds of interest. Following subcutaneous implantation in nude mice, host vascular endothelial cells will migrate 13 into the angioreactors and proliferate to form new blood vessels, if the compound of interest is angiogenic. In the presence of VEGF, used as a positive control, a strong induction of angiogenesis was observed (Figure 6C-6D). No significant blood vessels were observed in the vehicle (PBS or Fresh Media) control or with SERPINE1. Cylinders containing HGSOC cell lines conditioned media revealed extensive angiogenesis. The presence of erythrocytes inside the newly developed blood vessels indicated that they were functional. In contrast, conditioned media from HGSOC cell lines with PAX8 or SOX17 knocked down showed a significant decrease in ovarian cancer-induced neovascularization. These results show that ovarian cancer cell lines have the capacity to induce angiogenesis in vivo, and that PAX8 and SOX17 participate in this process probably through SERPINE1 down-regulation.

\section{Knockdown of PAX8 or SOX17 decreases tumor formation in an ovarian cancer xenograft} model.

Because we observed significant and reproducible effects of PAX8/SOX17 on angiogenesis, we hypothesized that knockdown of these genes may reduce the capacity of malignant cells to develop tumors in vivo. We employed a doxycycline-inducible lentiviral shRNA system in order to express shRNAs against PAX8 or SOX17 to deplete PAX8 or SOX17 levels in 3 different cancer cell lines (OVCAR3, OVCAR4, and OVTOKO). Unfortunately, OVCAR3 and OVCAR4 cells appeared to be exquisitely sensitive to the loss of PAX8 and SOX17 and we were unable to identify clones with acceptable levels of down-regulation. However, some OVTOKO clones exhibited efficient PAX8 or 
32 SOX17 knockdown and up-regulation of SERPINE1 after the induction with doxycycline (Figure 7A).

33 OVTOKO-shRNA harboring cells were injected intraperitoneally into NSG mice and incubated for 72

34 hours before doxycycline was added to the diet. After two weeks, control mice exhibited a significant

35 tumor burden (Figure 7B). Doxycycline treatment reduced the tumor burden further to an almost 36 undetectable level with no signs of ascites (Figure 7C-7D-7E), reinforcing our hypothesis that 37 PAX8/SOX17 are modulating tumor angiogenesis by suppressing anti-angiogenesis factors as 38 SERPINE1 and THBS1 (SI 7). These data show that inhibition of PAX8/SOX17 profoundly impairs the 39 growth of ovarian carcinoma cells in mice, part of these effects likely due to suppression of tumor angiogenesis. 


\section{DISCUSSION}

Many studies have implicated PAX8 as an important transcription factor in ovarian cancer. However, its mechanism of action in this regard remains unclear. Here, using a combination of biochemistry, in vitro models, and animal studies we make two important observations about how PAX8 governs tumor development. We show that PAX8 interacts with another developmental transcription factor, SOX17. PAX8 regulates expression of SOX17 and together they mediate a transcriptional program that drives angiogenesis in the malignant setting. Depletion of these proteins greatly attenuates angiogenesis in multiple systems.

Previous studies have shown that benign and malignant cells are distinguished by marked remodeling of the PAX8 cistrome and this implies that PAX8 may acquire new targets or functions in the malignant state (22). To investigate if the PAX8 re-distribution in cancer cells was due to changes in the PAX8 network, and to further clarify its roles in ovarian cancer, and possibly identify novel therapeutic opportunities, we first sought to identify its interacting partners in benign and malignant cells. Interestingly, its crucial role in transcriptional regulation was highlighted by our finding that multiple chromatin remodeling proteins interact with PAX8. Mechanisms of gene regulation by PAX8 are clearly complex as we found that, following PAX8 knockdown, a vast number of genes were up-regulated or down-regulated in these cells. A large number of the nucleosome remodeling molecules identified here are subunits of the NuRD complex, such as CHD4, MTA2, GATAD2A, GATAD2B, HDAC1, and RBBP4 suggesting that PAX8 participate in this chromatin-remodeling complex. Reinforcing these findings, a recent drug screen showed that PAX8 levels were strongly decreased by inhibitors of histone deacetylase (HDAC1) (31). Among the interacting partners identified, SOX17 was one of the mostly highly enriched in our mass spectrometry data. In addition, it exhibited a strong correlation and codependency with PAX8 in ovarian cancer using TCGA gene expression data. SOX17 is a transcription factor and member of the SOXF family, which has an HMG, $\beta$-catenin binding and transactivation domains (32). SOX17 biological function is always dependent on a dimerization partner (33) that is 
dynamic and specific to the cell context. SOX17-interacting partners can engage differentially in the

genome, regulating different sets of genes (34). Therefore, we hypothesized that the PAX8-SOX17

transcriptional activity may be crucial in ovarian tumorigenesis. We found that both PAX8 and SOX17

exhibit expression in the nuclei of both benign and malignant secretory cells, where they physically and

functionally interact. Our findings are in agreement with the current literature showing that PAX and

SOX members can engage in transcriptional regulation. Indeed, PAX3 and SOX10 can physically

interact and synergistically regulate MITF and c-RET enhancers (35). The PAX3-SOX10 interaction is

important for melanoma cells, where these factors regulate cell motility, apoptosis, and proliferation (36). Additionally, PAX6 and SOX2 are also interacting partners in early neural differentiation and are necessary for neural progenitor cell pluripotency (37). Furthermore, PAX6 and SOX2 act as an oncogene and can induce cancer cell stemness (38).

We found that PAX8 and SOX17 can mutually regulate each other at the transcriptional level. At

the protein level, PAX8 knockdown led to an almost complete disappearance of SOX17, and SOX17

knockdown led to a significant decrease in PAX8 levels. These results are reinforced by our recent

findings showing that PAX8 and SOX17 were found to be master transcription factors that occupy

regulatory elements related to their own encoding genes in ovarian cancer (39). Globally, PAX8 and

SOX17 genomic binding sites co-localize within candidate active enhancers in HGSOC cell lines. In

addition, PAX8 binds with high intensity near SOX17 gene locus, which confirms the co-regulation

observed in SOX17 transcript and protein levels (39). Here, using transcriptomic and proteomic analyses we showed that PAX8 and SOX17 commonly regulate a family of genes associated with blood vessel formation, suggesting a cooperative role in orchestrating an important pro-angiogenic transcriptional program in ovarian cancer. In this setting, it is interesting to note that murine Sox17 can 04 promote tumor angiogenesis and is regulated by the Notch pathway, known to contribute to 05 angiogenesis (40-43). 
Angiogenesis is a dynamic process rigorously regulated during embryogenesis, tissue

regeneration, and ovulation. However, angiogenesis can also abnormally occur during malignant

transformation $(44,45)$. Most of the angiogenesis mediators are secreted cytokines, but matrix

metalloproteinases and integrins also participate in new blood vessel development (46). The most

commonly secreted mediator in tumor angiogenesis is Vascular Endothelial Growth Factor (VEGF).

11 VEGF acts through its receptor (VEGFR2) and downstream effectors such as PLCy1 and ERK1/2.

12 Furthermore, VEGF signaling pathway abrogation has emerged as an attractive strategy of new

13 targeted anti-cancer therapy (47). Indeed, we found that PAX8 and SOX17 loss triggered a reduction

14 in angiogenesis both in vitro and in vivo model. We also observed a drastic decrease in tumor xenograft

15 growth following PAX8/SOX17 knockdown, and while we cannot rule out the roles of other cell intrinsic

16 processes, the decrease in angiogenesis is likely an important factor. It has been reported that patients

with high levels of VEGF have the worst prognostic and lower survival rates. Moreover, ovarian cancer

cells express on their surface VEGF receptors that contribute to angiogenesis and malignant

progression (48). The VEGF pathway is also responsible for the formation of ascites in patients with

ovarian tumors due to the elevated vascular permeability within peritoneal lining in the abdominal cavity

(49). Consistent with this fact, we found a significant decrease in ascites formation following knockdown of PAX8 and SOX17.

In trying to better understand the mechanisms of angiogenesis orchestrated by PAX8 and SOX17, we examined individual genes and identified those that were most affected by the knockdowns.

We found SERPINE1 to be the most highly commonly up-regulated gene both at the transcript level (using RNA-seq) and protein level (through RPPA). SERPINE1 is a serine proteinase inhibitor, belonging to the Serpin family, which is an important endothelial plasminogen activator inhibitor and urokinase inhibitor (50). Important roles in coagulation, extracellular matrix remodeling, and angiogenesis have been reported for SERPINE1. The anti-angiogenic effects of SERPINE1 seem to be mediated by binding to vitronectin and blocking $\alpha v \beta 3$ and uPAR binding sites (51). Therefore, 
31 binding of secreted SERPINE1 to vitronectin blocks cell adhesion, migration, and inhibits angiogenesis

(52). Moreover, vitronectin and integrin- $\alpha$ Vß3 strongly intensify VEGFR2 activation by VEGF (53).

SERPINE1 acts as an angiogenesis inhibitor by blocking the vitronectin-integrin-VEGFR2 axis and (SI 7).

Our results may also help explain some of the developmental defects described in the Pax8 knockout mouse (14). Pax8 $8^{-/-}$mice are infertile because they lack a functional uterus revealing only remnants of myometrial tissue. In addition, the vaginal opening is absent. Folliculogenesis, ovarian hormone production, and transcription of pituitary hormones are in a normal range. Thus, infertility in $\mathrm{Pax}^{-/-}$mice seems to be due to a defect in development of the reproductive tract rather than to hormonal imbalance, pointing to a direct morphogenic role for Pax8 in uterine development. Our observation that Pax8 and Sox17 orchestrate an angiogenic program may help explain the atresia of the reproductive tract seen in the $P a x 8^{-/}$mice. The absence of Pax8 in the developing reproductive tract is likely accompanied by low Sox17 and high Serpine1. These conditions would effectively shut down blood vessel development and prevent the development of the organ. This is reminiscent of the severe embryopathy seen with thalidomide in the early 1960s (54). Thalidomide was marketed as an anti-emetic which was later shown to have anti-angiogenic properties that cause severe birth defects, including phocomelia (limb defects), genital, and internal organ absence or malformation.

In summary, we have shown for the first time that PAX8 physically interacts with SOX17 in FTSEC and HGSOC leading to changes in multiple transcriptional programs, including modulation of genes mediating tumor angiogenesis. Further analyses of the genes regulated by PAX8/SOX17 
56 identified SERPINE1 as an anti-angiogenic factor that is suppressed by PAX8-SOX17 in cancer cells.

57 Knockdown of PAX8/SOX17 in this setting results in a decrease of blood vessel formation. Using cell58 based and animal models, we then functionally demonstrate that PAX8/SOX17 can regulate 59 angiogenesis during tumor development. Inhibition of tumor angiogenesis, perhaps through 60 PAX8/SOX17 pathway inhibition, has potential value as part of an anti-angiogenic approach to the 61 treatment of ovarian cancer $(40,55)$. 


\section{METHODS}

\section{Purification of endogenous PAX8}

Benign and malignant cells were grown in $15-\mathrm{cm}$ plates until $90 \%$ confluence, washed twice with PBS, trypsinized, neutralized and collected. Nuclear fractionation was prepared as previously published (24). Harvested cells were resuspended in hypotonic buffer [20 mM HEPES, pH 7.5, $10 \mathrm{mM} \mathrm{KCl}, 1 \mathrm{mM}$ EDTA, $1 \mathrm{mM}$ EGTA, $1.5 \mathrm{mM} \mathrm{MgCl}$, 2 mM dithiothreitol, protease inhibitors (Sigma-Aldrich: P8340), and phosphatase inhibitors (Sigma-Aldrich: P5726)] and incubated for 30 minutes. Samples were then disrupted through a $22 \mathrm{G}$ needle and centrifuged at $10,000 \times \mathrm{g}$ for 10 minutes at $4^{\circ} \mathrm{C}$. Nuclei-enriched 
88 fraction was sonicated with complete RIPA buffer (Cell Signaling: 9806S) containing protease inhibitors

89 (Sigma-Aldrich: P8340), and phosphatase inhibitors (Sigma-Aldrich: P5726), and spun down for 10 90 minutes at $10,000 \times \mathrm{g}$ at $4^{\circ} \mathrm{C}$. The supernatant $(500 \mu \mathrm{g}$ of nuclear extract) was incubated for 16 hours 91 at $4^{\circ} \mathrm{C}$ with $105 \mu \mathrm{g}$ of PAX8-specific antibody (Proteintech: 10336-1-AP) coupled to $1 \mathrm{ml}$ of Protein $\mathrm{A}$ agarose resin (Thermo-Fisher: 44893) or with $105 \mu \mathrm{g}$ of normal rabbit IgG (Proteintech: 30000-0-A)

coupled to $1 \mathrm{~mL}$ of Protein $\mathrm{A}$ agarose resin, as negative control. The columns were washed three times with $10 \mathrm{~mL}$ of $0.1 \mathrm{M}$ phosphate and $0.15 \mathrm{M} \mathrm{NaCl}, \mathrm{pH} 7.2$ and eluted with $0.5 \mathrm{M} \mathrm{NaCl}$ and $0.1 \mathrm{M}$ glycine, $\mathrm{pH}$ 2.8. Fractions had their $\mathrm{pH}$ equilibrated with $1 \mathrm{M}$ Tris, $\mathrm{pH} 9.5$, separated by gel electrophoresis, Coomassie blue-stained and lanes were sent for mass spectrometry analysis.

The affinity column eluates containing PAX8 were also loaded in $100 \mathrm{ml}$ of Sephacryl S-300 column (Sigma-Aldrich: S300HR-100ML) equilibrated with 50mM Tris, pH 7.5, $100 \mathrm{mM} \mathrm{KCL}, 0.5 \mathrm{M}$ $\mathrm{NaCl}, 1 \% \mathrm{NP}-40$ and $1 \%$ glycerol. We collected one hundred and fifty $500 \mu \mathrm{L}$ fractions and protein peaks were separated by gel electrophoresis, silver-stained (Thermo-Fisher: 24600), checked by WBs for the presence of PAX8, and positive-samples were also sent for mass spectrometry analysis.

\section{PAX8 interacting-partners identification}

Coomassie blue-stained lanes containing PAX8 were analyzed by nanoLC-MS/MS setup as previously described (57). In summary, HPLC gradient was set between $0-30 \%$ of solvent $A=0.1 \%$ formic acid and solvent $\mathrm{B}=95 \%$ acetonitrile, $0.1 \%$ formic acid for one hour followed by five minutes of $30 \%$ to $85 \%$ of solvent $B$ and ten minutes of isocratic $85 \%$ solvent $B$. Flow rate of $n L C$ was set to 300 $\mathrm{nL} / \mathrm{min}$ and coupled to Orbitrap Fusion Tribrid mass spectrometer (Thermo Fisher, USA) with $2.5 \mathrm{kV}$ spray voltage and $275^{\circ} \mathrm{C}$ of capillary temperature. Full mass spectrometry was performed using a resolution of 120,000 and 27 of $H C D$. 
11 DDA files were analyzed with MaxQuant (58) using a SwissProt human database. iBAQ quantification

12 was used for enrichment analysis and data were log2 transformed and normalized by subtracting the 13 average of all valid values for each sample. Statistics analysis was obtained applying a two-tails 14 heteroscedastic t-test.

16 Co-immunoprecipitation.

$500 \mu \mathrm{g}$ of nuclear lysates were incubated with $25 \mu \mathrm{g}$ of a specific PAX8-antibody (Novus: NBP1-

32440), $25 \mu \mathrm{g}$ of a specific SOX17-antibody (Abcam: ab224637), or $25 \mu \mathrm{g}$ of a normal rabbit IgG (Cell

Signaling: 2729S) covalently-coupled to activated agarose beads (Thermo-Fisher: 26148) as manufacturer's recommended protocol.

\section{Conditioned medium}

Secretory cells and carcinoma cells were growth in $60 \mathrm{~mm}$ dish at $37{ }^{\circ} \mathrm{C}$ and $5 \% \mathrm{CO}_{2}$.

\section{Immunohistochemistry}

Fallopian tube and high-grade ovarian carcinoma sections were processed as previously reported (59). The immunohistochemical staining were performed using a dilution of 1:500 of anti-PAX8 antibody (Novus: NBP1-32440) or a dilution of 1:500 of anti-SOX17 antibody (Novus: NBP1-47996).

31 Slides were scanned with Aperio CS2.

Immunofluorescence

Ten thousand FTSEC and HGSOC cells were seeded on imaging plates (Eppendorf: 35 0030741030) and allowed to grow for 24 hours. Following cells were washed twice in PBS and fixation 
36 was performed for 15 minutes on Paraformaldehyde 4\% (Thermo-Fisher: AAJ19943K2) at room

temperature. After the incubation period, cells were washed twice in PBS and permeabilized with Triton

X-100 0.25\% (Boston BioProducts: P-924) for 15 minutes. Aldehydes residues were quenched with

\section{in situ Protein-protein interaction analysis}

Prior to the protein-protein interaction staining by in situ proximity ligation assay (PLA), tissue sections and cell lines were processed as described in the IHC and IF sections. PLA signals were determined employing Duolink Probes Anti-Mouse MINUS (Sigma-Aldrich: DUO92004) and AntiRabbit PLUS (Sigma-Aldrich: DUO92002) as manufacturer's recommended protocol following overnight incubation with anti-PAX8 mouse antibody 1:250 (Novus: NBP2-29903) and anti-SOX17 rabbit antibody 1:250 (Cell Signaling: $81778 S$ ) at $4{ }^{\circ} \mathrm{C}$. Red fluorescent signals was obtained using detection reagent red (Sigma-Aldrich: DUO92008) and chromogen signals was acquired using detection reagent brightfield (Sigma-Aldrich: DUO92012).

\section{siRNA knockdown}

Fallopian tube secretory and ovarian carcinoma cells knockdowns were performed by reverse transfection with a mixture containing of $30 \mathrm{nM}$ of ON-TARGETplus Human PAX8 siRNA 
61 (Dharmacon:L-003778-00-0005), ON-TARGETplus Human SOX17 siRNA (Dharmacon: L-013028-01-

62 0005) or non-targeting siRNA as negative control (Dharmacon: D-001810-10-05), $3 \times 10^{5}$ cells, $10 \mu l$ 63 of Lipofectamine RNAiMax (Thermo-Fisher: 13778075), and Opti-MEM reduced serum medium (Gibco: $6431985088)$ as recommended by the manufacturer's protocol.

\section{Western blot analysis}

Samples were incubated with RIPA buffer (Cell Signaling: 9806S) for 30 minutes at $4^{\circ} \mathrm{C}$ followed

by centrifugation at $10,000 \times \mathrm{g}$ for 5 minutes. Supernatants' protein concentration was estimated by

BCA method (Thermo-Fisher: 23227). Thirty micrograms of each sample were mix with sample buffer

loaded and separated using Mini-PROTEAN TGX 4-15\% polyacrylamide gels (BioRad: 4561083) and Tris/Glycine/SDS buffer (BioRad: 1610732). TURBO transfer system (BioRad: 1704156) was employed

to move separated samples from gels to PVDF membranes. Primary antibodies: anti-PAX8 (Novus: NBP1-32440), anti-SOX17 (Abcam: ab224637) or anti-GAPDH (Cell Signaling: 5174) were diluted

$1: 1000$ in $5 \%$ nonfat milk in TBS containing $0.1 \%$ Tween 20 and incubated with the membranes overnight at $4^{\circ} \mathrm{C}$. After the period of incubation, membranes were washed three times with TBS containing $0.1 \%$ Tween 20 then incubated with anti-Rabbit IgG-HRP conjugated (Cell Signaling: 7074). Images were acquired by chemiluminescence using Clarity ECL (BioRad: 1705062).

\section{Real-time PCR}

Samples total RNA was purified using the RNeasy Plus Mini Kit (Qiagen: 74134), quantified and used as a template for the synthesis of single-stranded cDNA employing the High Capacity cDNA Reverse Transcription Kit (Thermo-Fisher: 4374966). To access the gene expression changes we employed the TaqMan Assay (Thermo-Fisher: 4331182) using $100 \mathrm{ng}$ of cDNA per $20 \mu \mathrm{L}$ of final reaction with TaqMan Fast Advanced Master Mix (Thermo-Fisher: 4444557) as recommended by manufacturer's protocol. 


\section{RNA-seq}

Transcriptome analysis of OVCAR4 cells after PAX8, SOX17 or both knockdown simultaneously was performed as previously described $(39,60)$. In summary, ovarian carcinoma cells had their RNA chemically purified using the Nucleospin RNA Plus kit (Macherey-Nagel: 740984.50) as recommended by the manufacturer's protocol. Poly-A non-stranded library were prepared using the newly extracted RNA and forty million reads were sequenced by BGI platform. Bioinformatic analyses were executed employing the R package DESeq2 (version 1.24.0). Significant changes were designated as log2 fold change $\geq 1$ and adjusted $p$-value $\leq 0.01$. Metascape tool was employed to identify the differentially enriched pathways.

\section{Reverse-phase protein array}

Arrays were performed at the Department of Bioinformatics and Computational Biology in MD Anderson Cancer Center as previously described $(61,62)$. The platforms contains over 300 antibodies exclusively validated with a Pearson coefficient $>0.7$ of correlation between RPPA and WB were employed in the proteomic analysis (63). Spots intensities were generated by colorimetric reaction employing the Dako Cytomation-Catalyzed System.

\section{Luciferase reporter assay}

Briefly, half-million cells were co-transfected with $1 \mu \mathrm{g}$ of PAX8-(Firefly) Luciferase reporter vector (27), $0.5 \mu \mathrm{g}$ of CMV-(Renilla) Luciferase control vector (Promega: E2261) and $30 \mathrm{nM}$ of PAX8, SOX17 or Non-targeting siRNA, using Lipofectamine 2000 (Thermo-Fisher: 11668027) as recommended by manufacturer's protocol. Plates containing the different transfected cells were incubated for 24 hours at $37^{\circ} \mathrm{C}$ before the luciferase activity was measured using the Dual-Glo luciferase detection kit (Promega: E2920). 
11 Array and ELISA

Angiogenesis secreted mediators were identified from fallopian tube secretory cells and ovarian

carcinoma cells conditioned media employing the Human Angiogenesis Antibody Array (R\&D systems:

14 ARY007). ELISA was employed for the precise quantification of VEGF (R\&D systems: DVE00) and

SERPINE1 (R\&D systems: DSE100) also from cells conditioned media as recommended by the

manufacturer's protocol. Fresh DMEM/F12 or RMPI media were tested and considered as the negative control.

\section{In vitro angiogenesis assay}

Twenty thousand HUVEC cells were seeded in reduced growth factor basement membrane extract (BME)-coated 96-well plate (R\&D systems: 3470-096-K). Endothelial cells were exposed to 100 $\mu \mathrm{l}$ of the different benign or malignant cells conditioned media, $10 \mathrm{ng} / \mathrm{ml}$ VEGF (R\&D systems: 293-VE010) or $10 \mu \mathrm{g} / \mathrm{ml}$ SERPINE1 (R\&D systems: $1786-P I-010)$ for $6 \mathrm{~h}$ at $37^{\circ} \mathrm{C}$. HUVEC cells were labeled with $2 \mu \mathrm{M}$ Calcein $\mathrm{AM}$ as recommended by the manufacturer's protocol to facilitate the image acquisition using a Nikon Eclipse Ti inverted microscope. The number of complete endothelial loops per field were counted and compared.

\section{In vivo angiogenesis assay}

Following IACUC review and approval (Protocol \#806687), in vivo angiogenic responses were analyzed by directed in vivo angiogenesis assay (DIVAA) (R\&D systems: 3450-048-K) as recommended by the manufacturer's protocol. Briefly, six-week female nude mice (JAX: 002019) were kept in aseptic condition under the Stem Cell and Xenograft Core barrier at the University of Pennsylvania. Mice cohorts were anesthetized with $2 \%$ isoflurane prior the subcutaneously implantation of angioreactors i.e. one-centimeter flexible silicone cylinder. Dorsal-lateral incisions were made on each nude mouse, where angioreactors filled with FTSEC or HGSOC conditioned media, 10 
ng/ml VEGF (R\&D systems: 293-VE-010) or $10 \mu \mathrm{g} / \mathrm{ml}$ SERPINE1 (R\&D systems: 1786-PI-010) were

subcutaneously inserted under the skin and then sutured to cover the incisions. Angioreactors were

retrieved after 14 days of incubation for careful collection of the mouse endothelial cells that were

attracted and invaded the cylinders. Neovascularization was quantified by staining the endothelial cells

with FITC-lectin and measuring the intensity of fluorescence within a Thermo-Fisher Fluoroskan Ascent

FL fluorimeter at $485 \mathrm{~nm}$. protocol.

\section{Doxycycline inducible knockdown}

We employed Dharmacon SMARTvector inducible lentiviral shRNA that utilize the Tet-On 3G bipartite induction system and TurboGFP as a fluorescent reporter. This tightly regulated system consists of an inducible RNA polymerase II promoter, Phosphoglycerate kinase (PGK), which has been optimized for both minimal basal expression and potent activation upon induction by doxycycline on the TRE3G. Together, the Tet-On 3G protein and TRE3G promoter permit tight regulation of the shRNA expression, including potent induction, even at the low doxycycline doses that are required for in vivo xenograft studies. The selected shPAX8 (Dharmacon: V3IHSPGG-8017023), shSOX17 (Dharmacon: V3IHSPGG-6371478) and Non-Targeting Control (Dharmacon: VSC6580) high-titer lentivirus were used to transduce OVCAR3, OVCAR4 and OVTOKO cells as recommended by the manufacturer's

\section{Generation of Luciferase-expressing cells}

Ovarian cancer cell lines $\left(5 \times 10^{4}\right.$ cells per 24 well) in complete media containing $8 \mu \mathrm{g} / \mathrm{mL}$ Polybrene (Millipore-Sigma: TR-1003-G) were transduced with high-titer Luc-mCherry lentivirus (64). Lentivirus was produced with 3rd Generation Packaging System Mix (Abcam: LV053) in 293T cells transfected with Lipofectamine 3000 Reagent (Thermo-Fisher: L3000008) in OPTI-MEM medium 
60 (Gibco: 31985-062). In order to produce high-titer particles, 293T transfected cells conditioned media

61 were condensed with the Lenti-X Concentrator (Clontech: 631231 ) at $4^{\circ} \mathrm{C}$ for 24 hours.

\section{Mice xenograft}

Following IACUC review and approval (Protocol \#806825), one million OVTOKO harboring shRNA-luciferase-positive cells were inoculated intraperitoneally into five-six weeks old female immunodeficient NSG mice (JAX: 005557). All NSG mice cohorts were aseptically housed under the

Stem Cell and Xenograft Core barrier. After 72 hours post-injections, feeding supplemented with $1 \mathrm{~g} / \mathrm{kg}$ of doxycycline (Teklad: TD.06294) was made continuously available for the mice. Tumor progression was examined by bioluminescence imaging using the Lumina IVIS system and $150 \mathrm{mg} / \mathrm{kg}$ of Luciferin (Gold Biotechnology, 115144-35-9) in PBS. Animals were sacrificed when they reached IACUC pre71 determined endpoints for ascites and tumor collection.

\section{Statistical analysis}

Representative graphics are displayed as mean and standard derivation of experiments replicates. Significant changes $P<0.05$ between controls and knockdowns were acquired applying Student's test (GraphPad Prims 8). 

.

\section{ACKNOWLEDGMENTS}

We recognize the Drapkin laboratory members for their helpful consideration and support in especially Kai Doberstein. We also acknowledge Cynthia Lopez-Haber for her technical insights, Gregory Dressler for sharing the PAX8-Luciferase reporter vector, and Andrew Kung for donating the FUW-Luc-mCherry vector. In addition, we are very grateful for the Stem Cell \& Xenograft Core, the Quantitative Proteomics Resource Core, and the MD Anderson RPPA Core (NCI P30 CA16672) for technical assistance and resource access. We are also very appreciative of Tony Secreto and Lauren Schwartz support and expertise.

This work was supported by an NIH SPORE in ovarian cancer P50 CA228991 (R.D.), the Dr.

Miriam and Sheldon G. Adelson Medical Research Foundation (R.D.), the Honorable Tina Brozman Foundation for Ovarian Cancer Research (R.D.), the Basser Center for BRCA (R.D.), the Claneil Foundation (R.D.), an NIH P01CA196539 (B.A.G), the Ann and Sol Schreiber Mentored Investigator Award (545754) from the Ovarian Cancer Research Alliance (D. C-M), and the Liz Tilberis Early Career Award (599175), also from the Ovarian Cancer Research Alliance (K.L.). 


\section{FIGURES}

Figure 1: Three-step proteomic approach identifies putative PAX8-interacting partners. (a) Schematic of the workflow for the PAX8-interacting partner's identification. (b) Representative examples of endogenous PAX8 immunoprecipitation silverstained gel and immunoblot from fallopian tube secretory cells (FT) and ovarian carcinoma cells (OV). IMR90 cells, which are PAX8 negative, were used as negative control (C). (c) Immunoblot of size-exclusion fractions showing the presence of PAX8 at $600 \mathrm{kDa}$ size range. PAX8 immunoprecipitates and gel-filtration fractions were sent for mass spectrometry analysis. (d) Volcano plot of identified putative PAX8-interacting partners. (e) Confirmation of PAX8 and SOX17 interaction by coimmunoprecipitation experiments from FTSEC and HGSOC cell lines. (f) PAX8 and SOX17 immunoblots of size exclusion fractions demonstrate co-elution at $600 \mathrm{kDa}$ size range fractions.
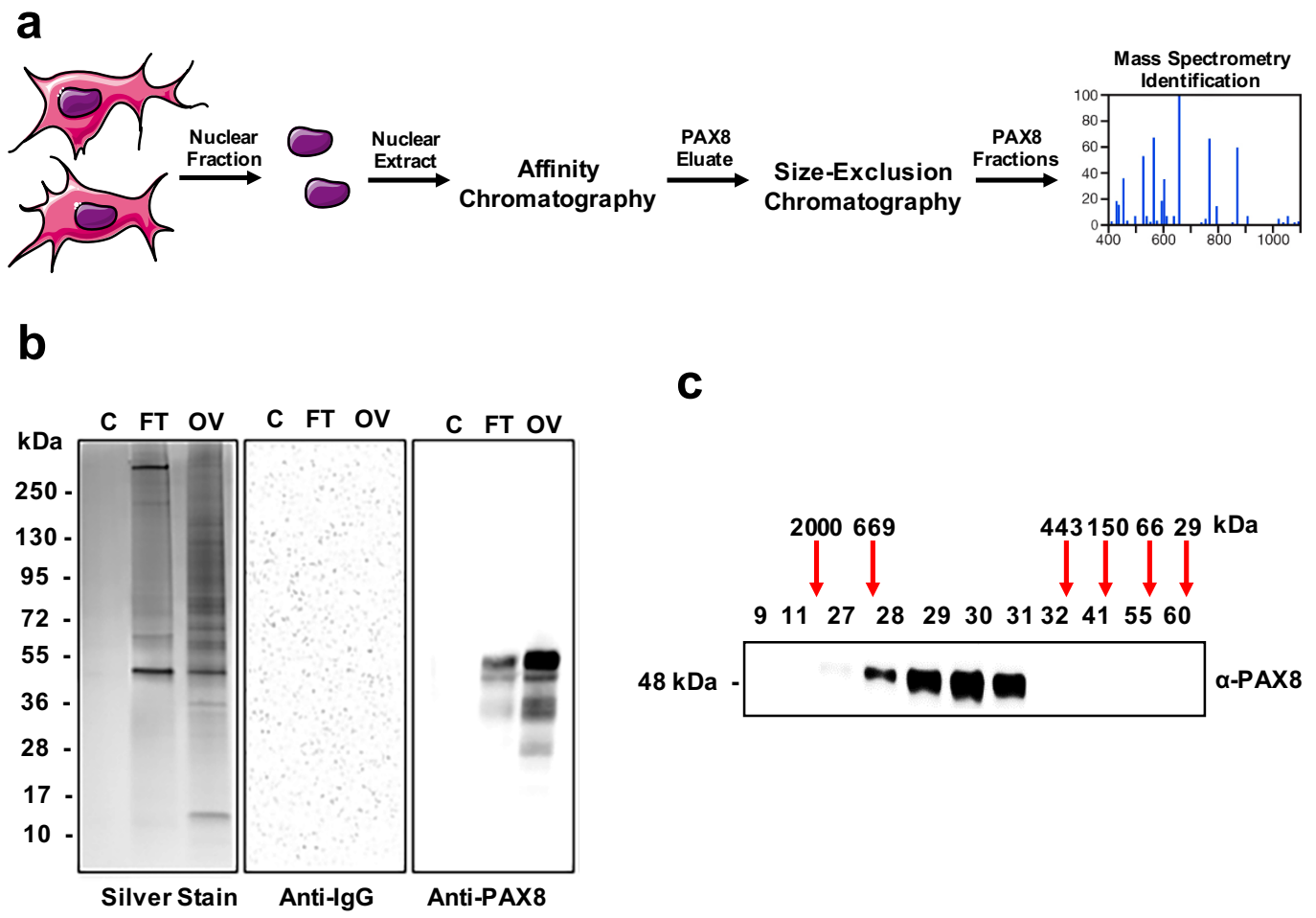

C

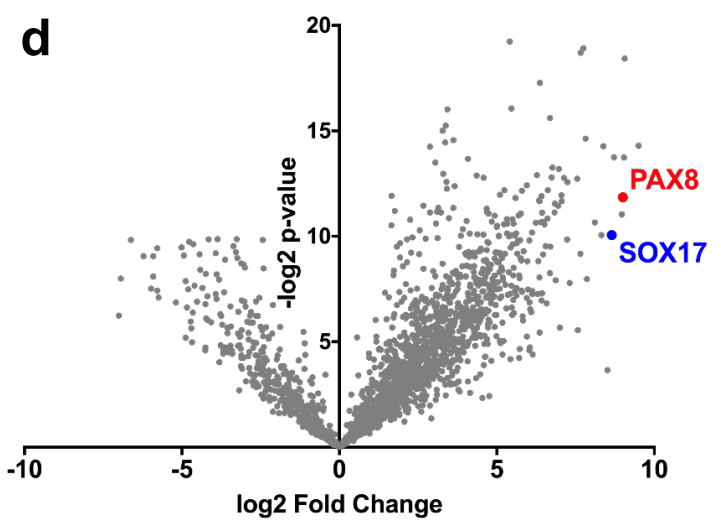

\section{e}
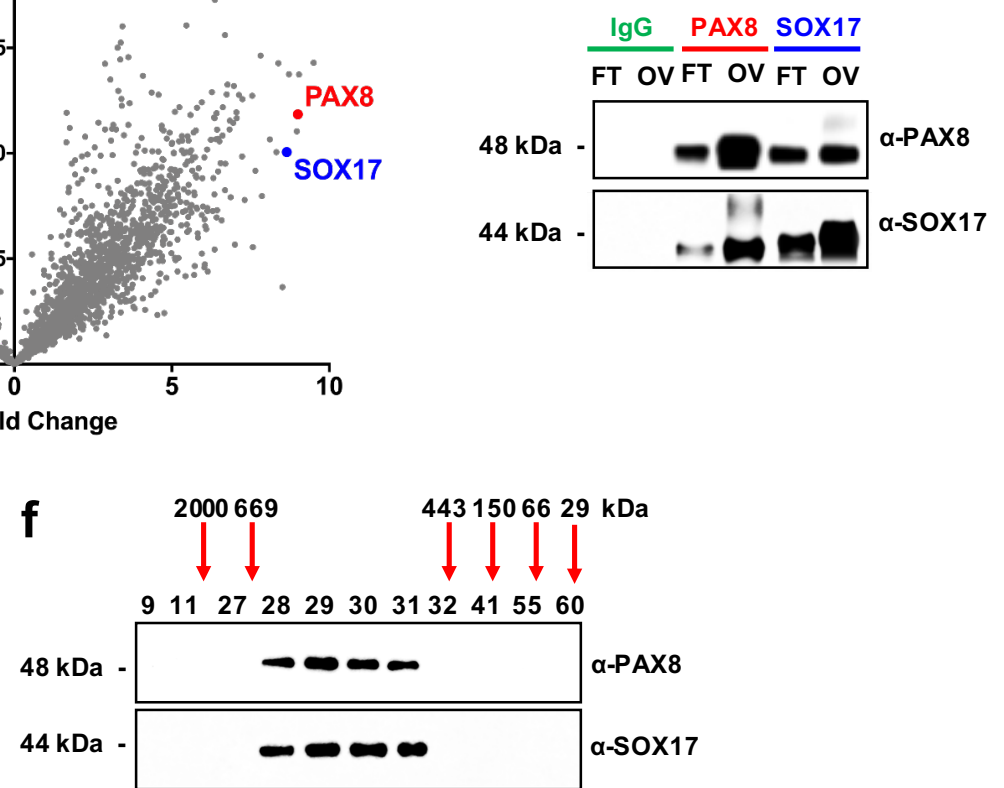
Figure 2: PAX8 physically interacts with SOX17 in the fallopian tubes and in ovarian cancer. (a) Immunohistochemistry showing nuclear co-expression of PAX8 and SOX17 in FTSEC and HGSOC cells. 5 normal samples and 5 ovarian cancer patients were analyzed and one representative case of each is shown. (b) Immunofluorescence showing co-localization of PAX8 and SOX17 in benign cells (FT194, FT246, and FT282) and in malignant cells (OVCAR4, KURAMOCHI, and OVSAHO). (c) Proximity ligation assay signals in secretory cells (FT194, FT246, and FT282) and in carcinoma cells (OVCAR4, KURAMOCHI, and OVSAHO) are shown in red. The nuclei are stained with DAPI (blue). The nuclei were acquired in one z-plane with 60X magnification. (d) In situ proximity ligation assay signals in normal fallopian tube sections and high-grade serous ovarian cancer samples shown in brown and the nuclei in orange. The nuclei were acquired in one z-plane with 40x magnification. *Number of PLA signals (PAX8-SOX17 interactions) was determined by counting 100 nuclei per sample (Supplemental information 2).

(1)
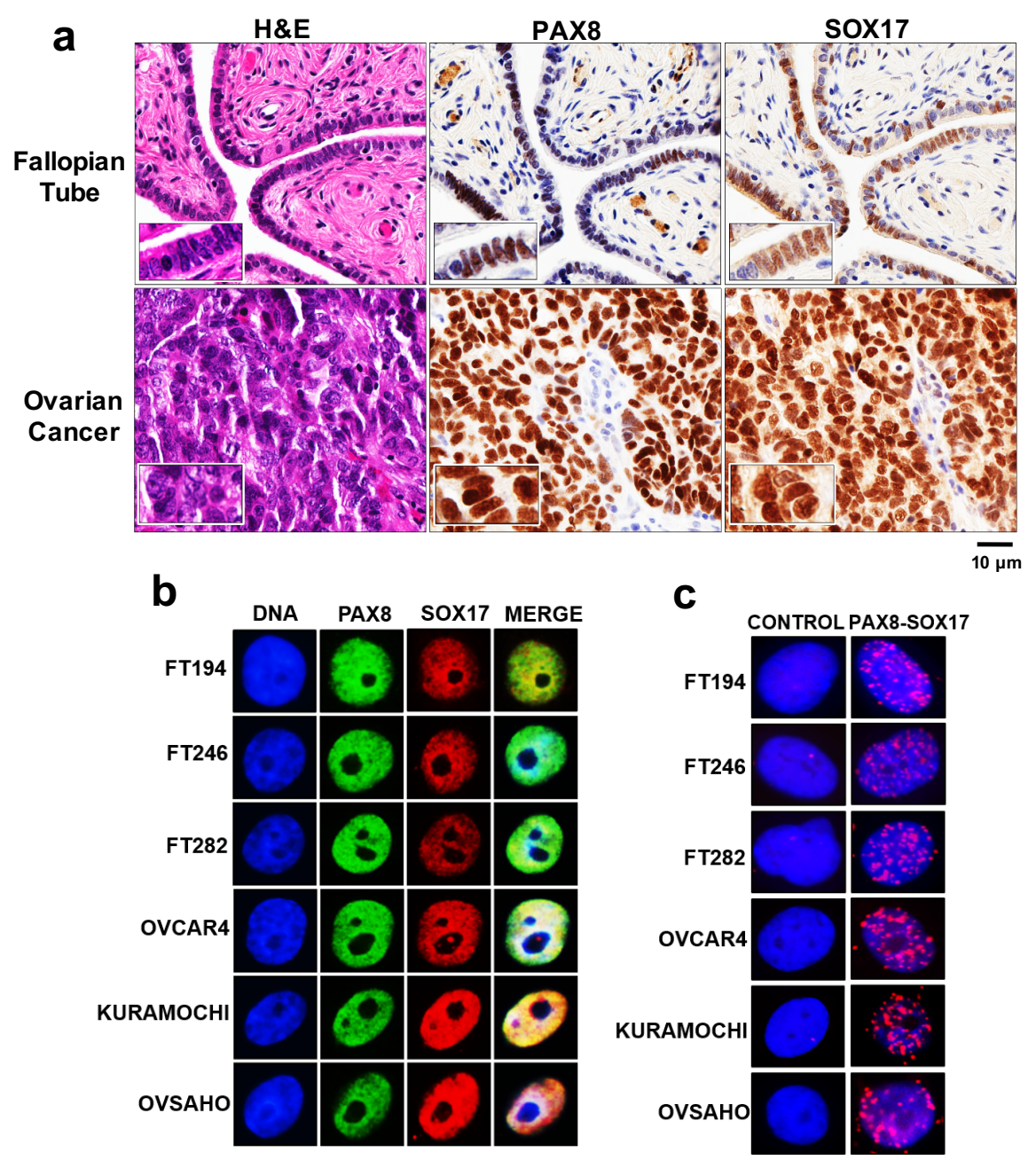

\section{d}
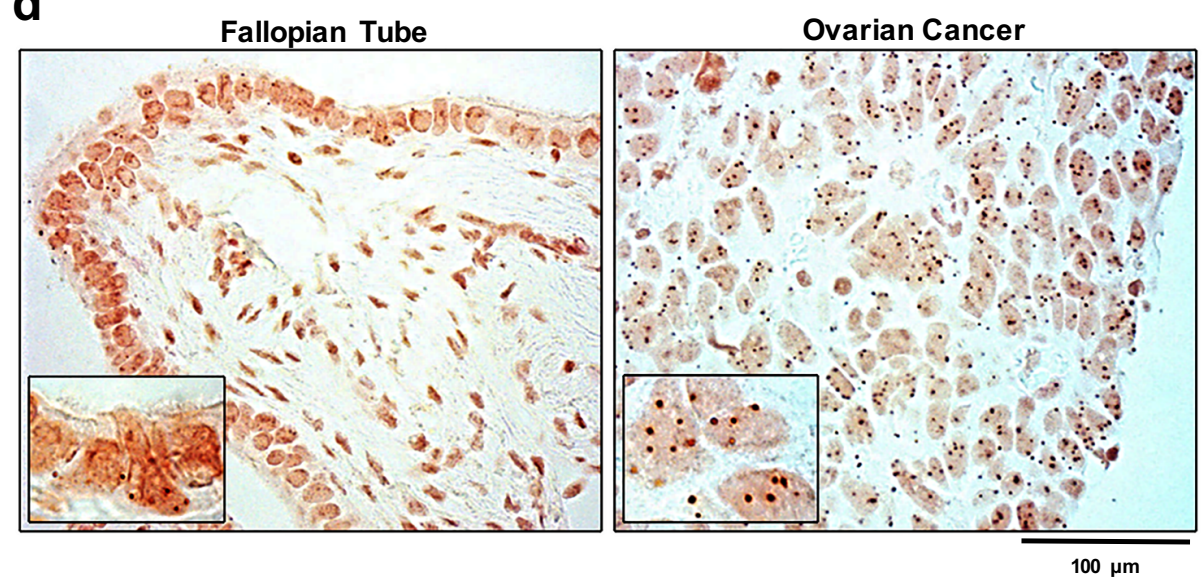
a $\quad$ b

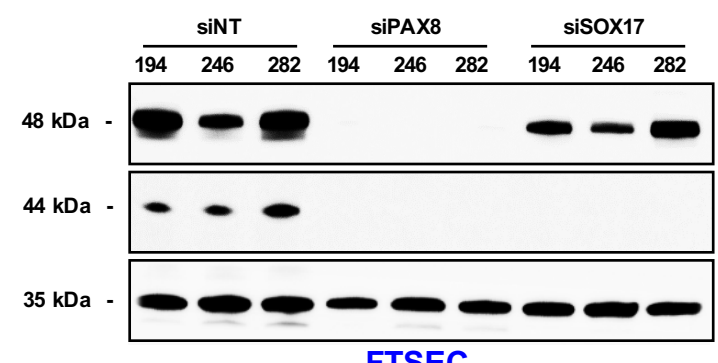

FTSEC

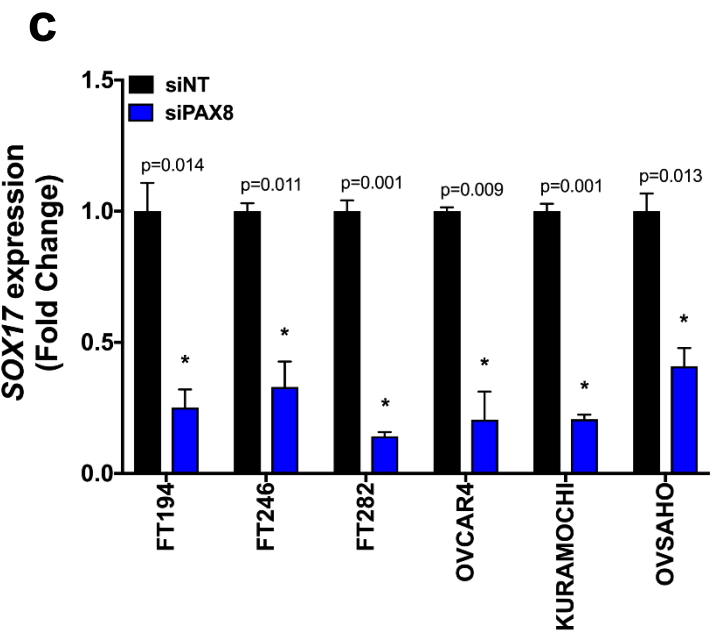

d

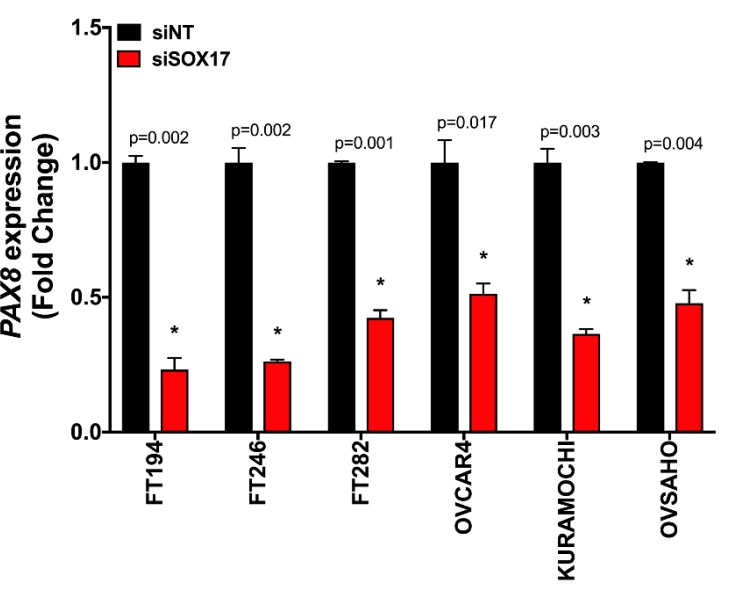

e

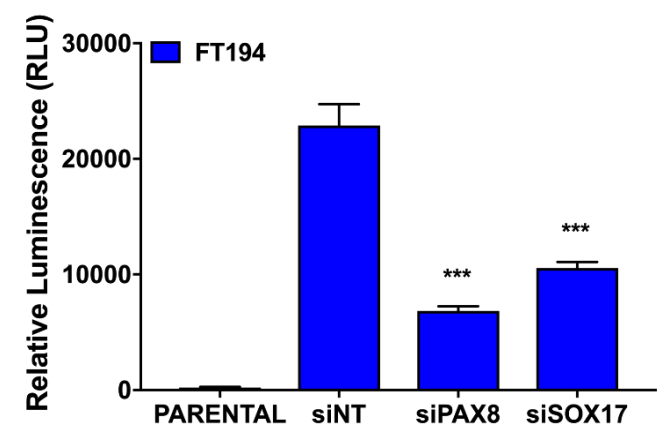

b

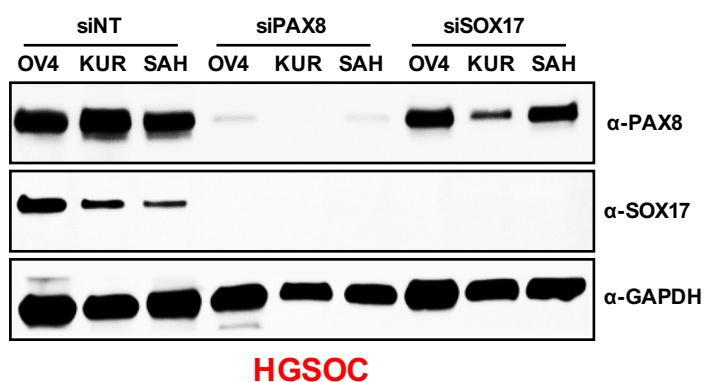

HGSOC

f

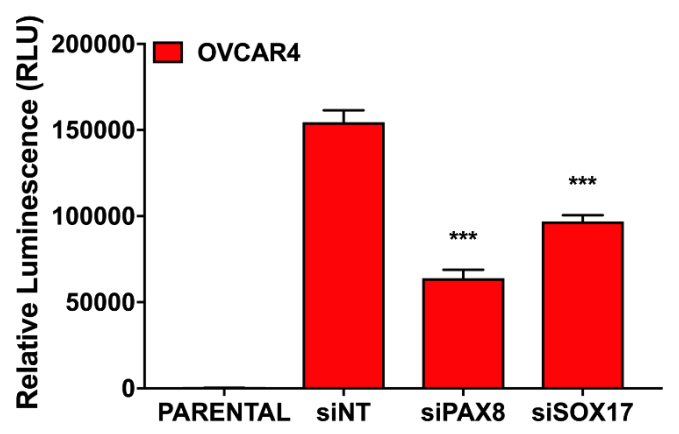


a

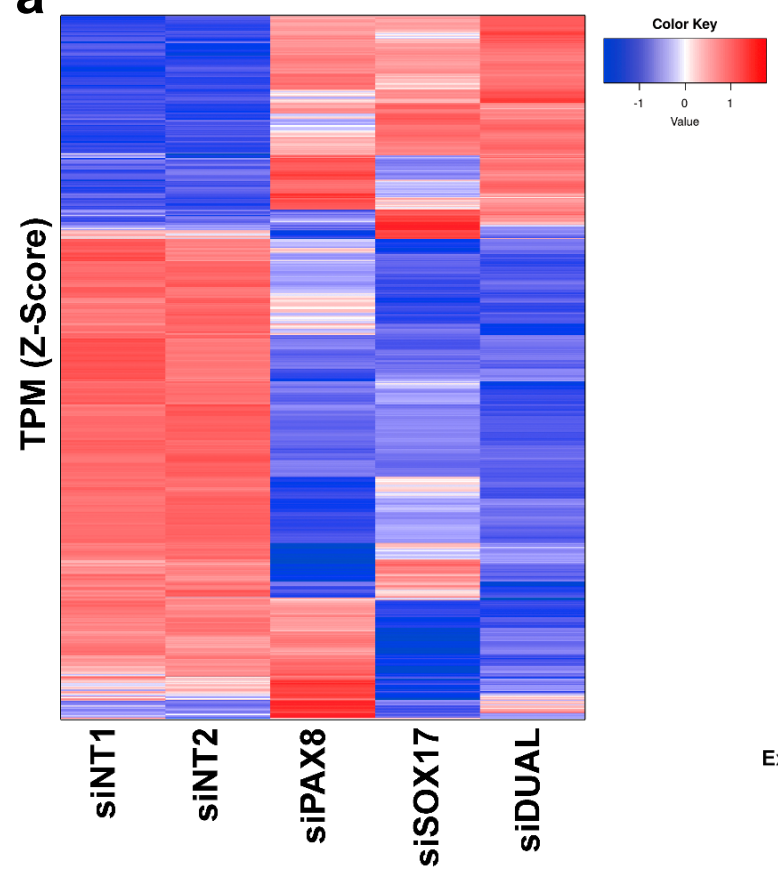

b

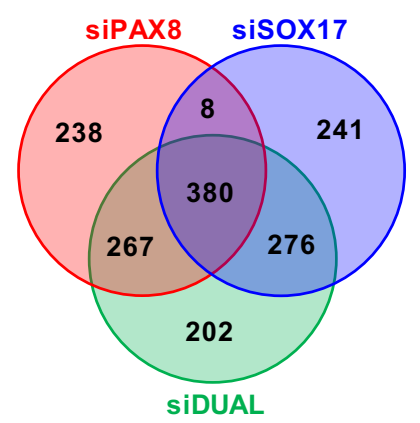

Up-regulated genes

C

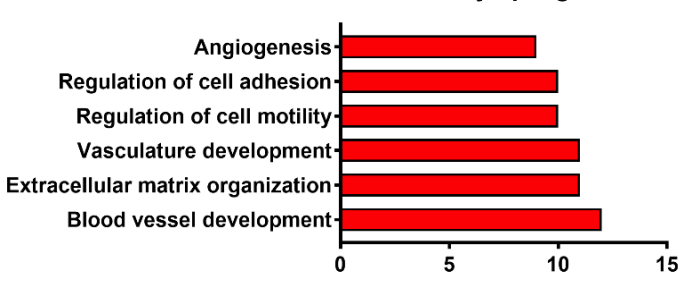

Figure 4: PAX8 and SOX17 regulate a common set of genes. (a) RNA-seq unsupervised clustering of PAX8, SOX17, and commonly regulated target genes. Profiles obtained with OVCAR4 after $72 \mathrm{hr}$ knockdowns; fold change $>1$; $P<0.05$. (b) Venn diagram representing number of genes up-regulated under each condition. (c) Ontology analysis of the PAX8-SOX17 commonly up-regulated genes. (d) RPPA unsupervised clustering of PAX8-SOX17 commonly regulated proteins. (e) Topranked PAX8-SOX17 commonly regulated proteins. (f) Immunoblot showing SERPINE1 up-regulation after PAX8 or SOX17 knockdown. (g) Real-time PCR showing SERPINE1 up-regulation after PAX8 or SOX17 knockdown. 5 ,

(1)

8

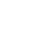
.
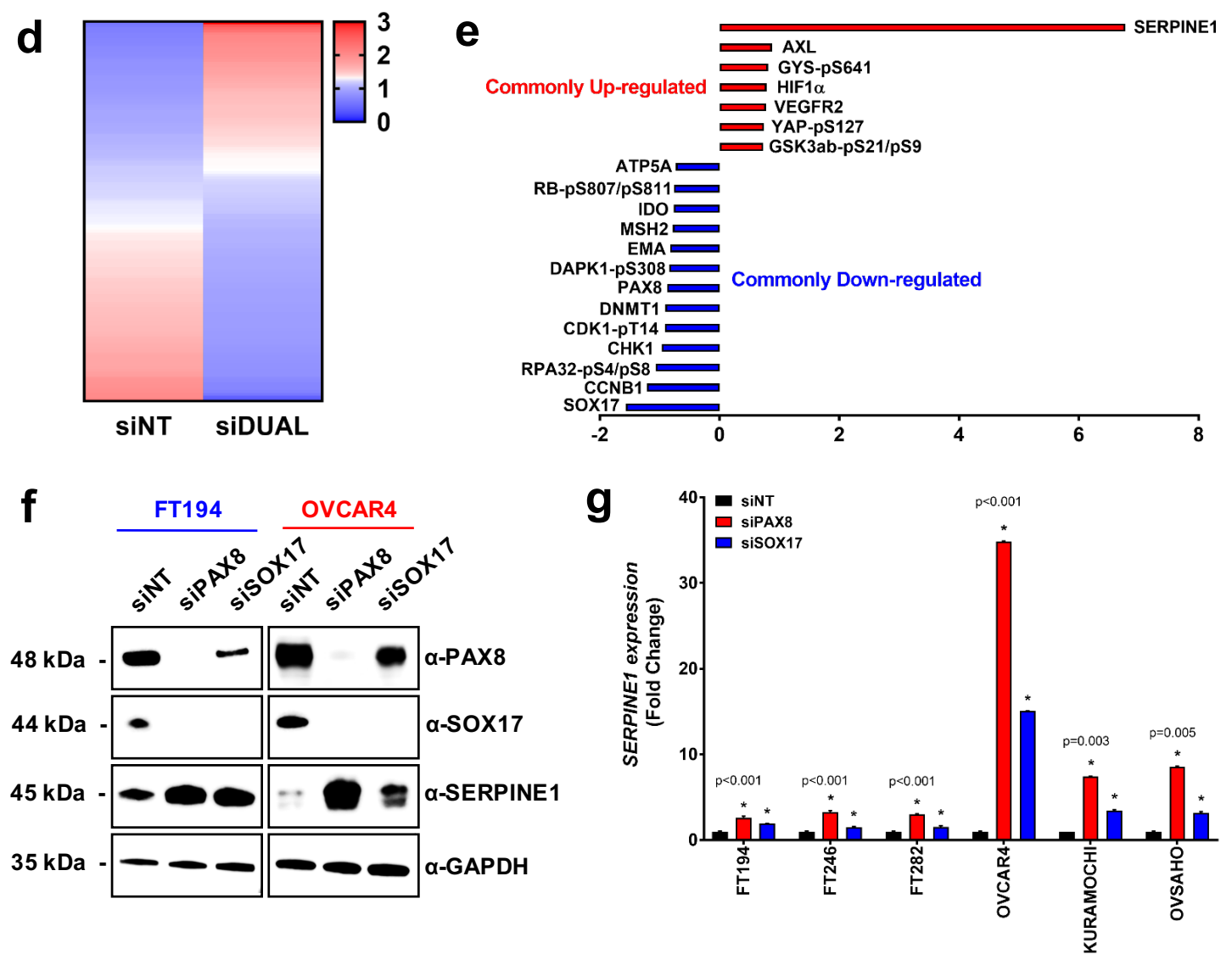
a

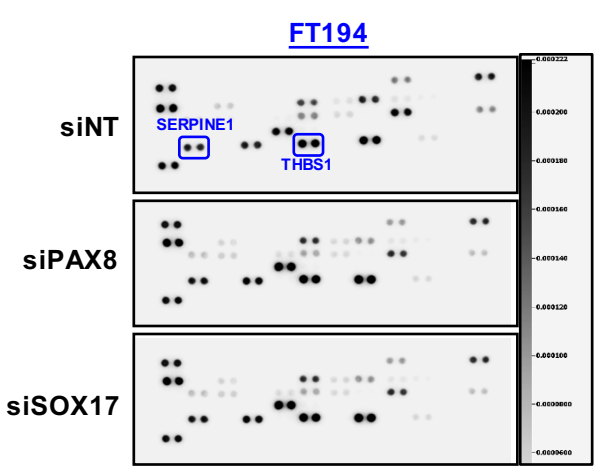

b

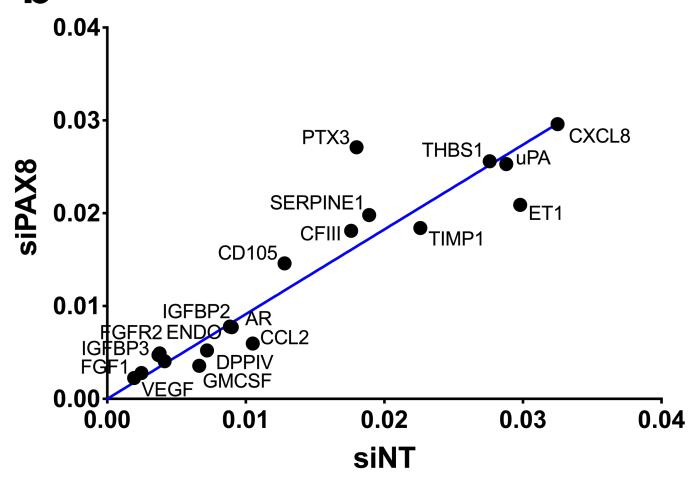

C

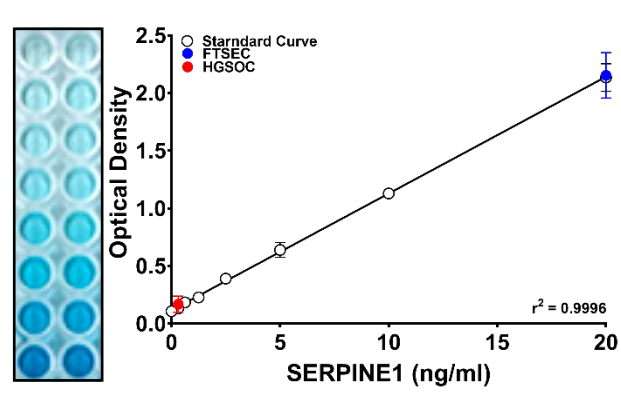

e

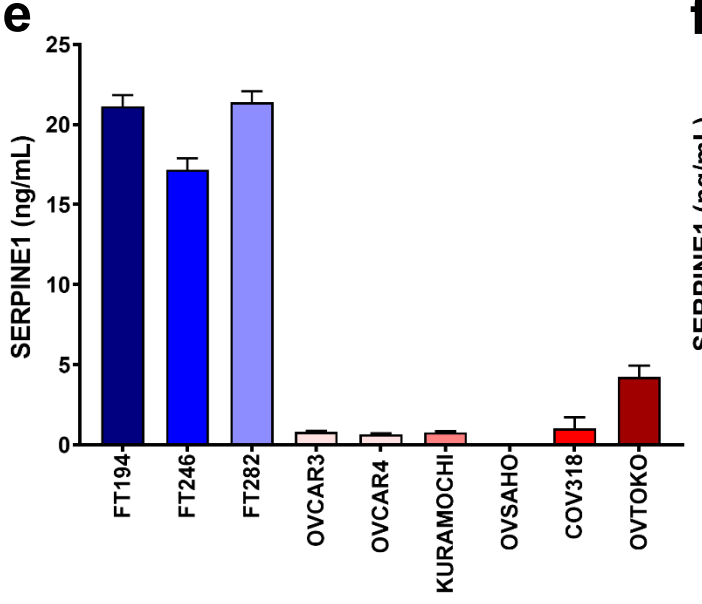

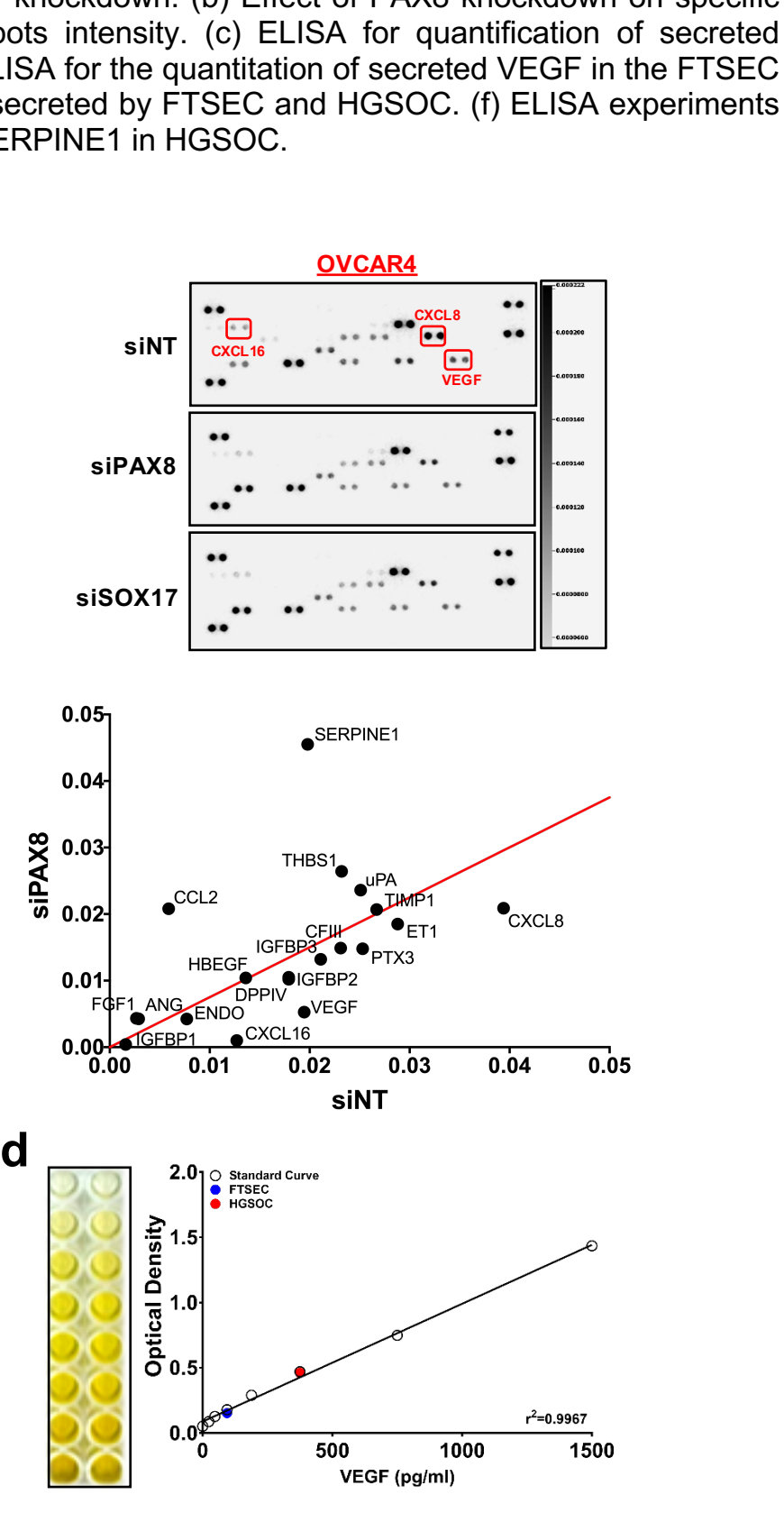

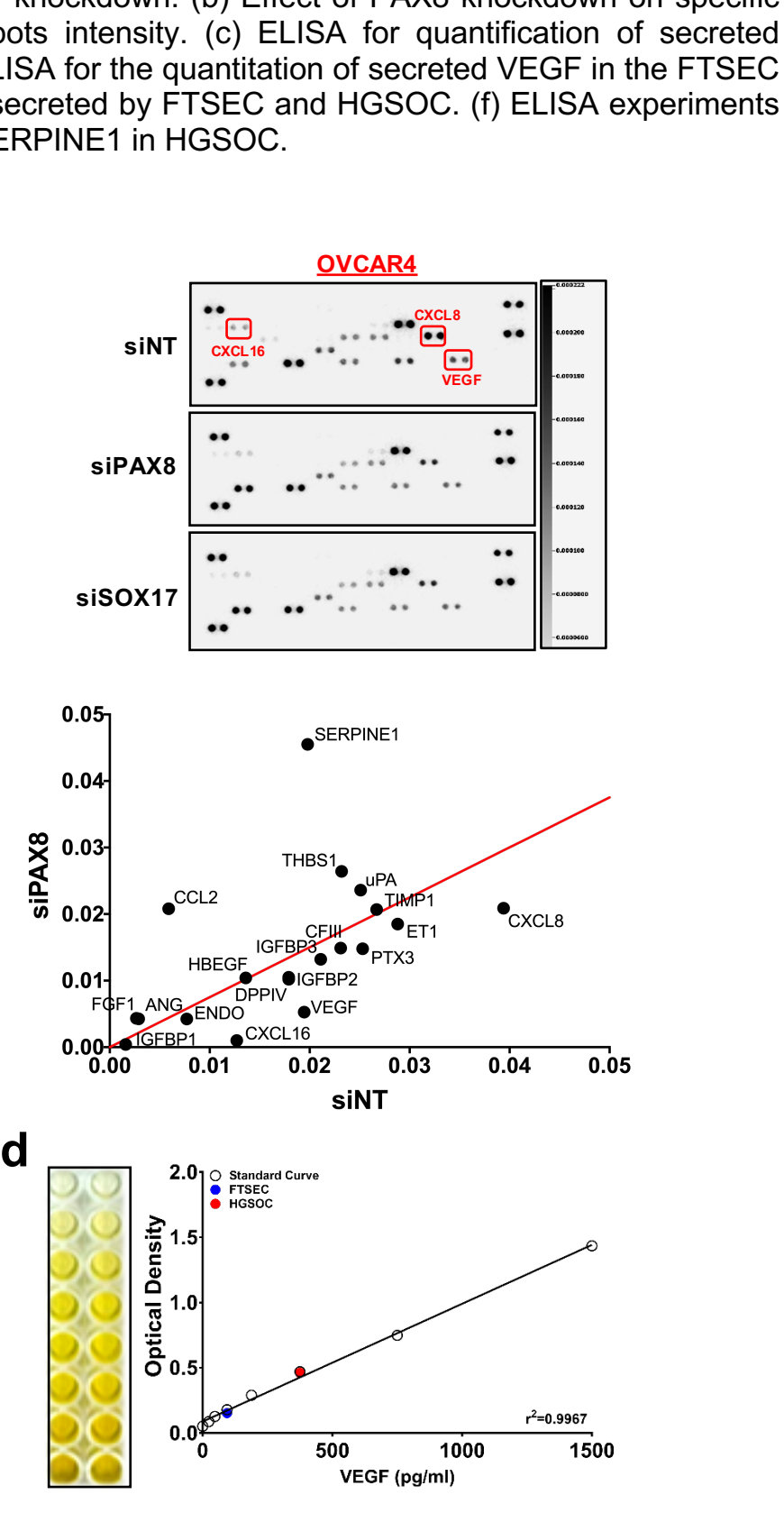

d

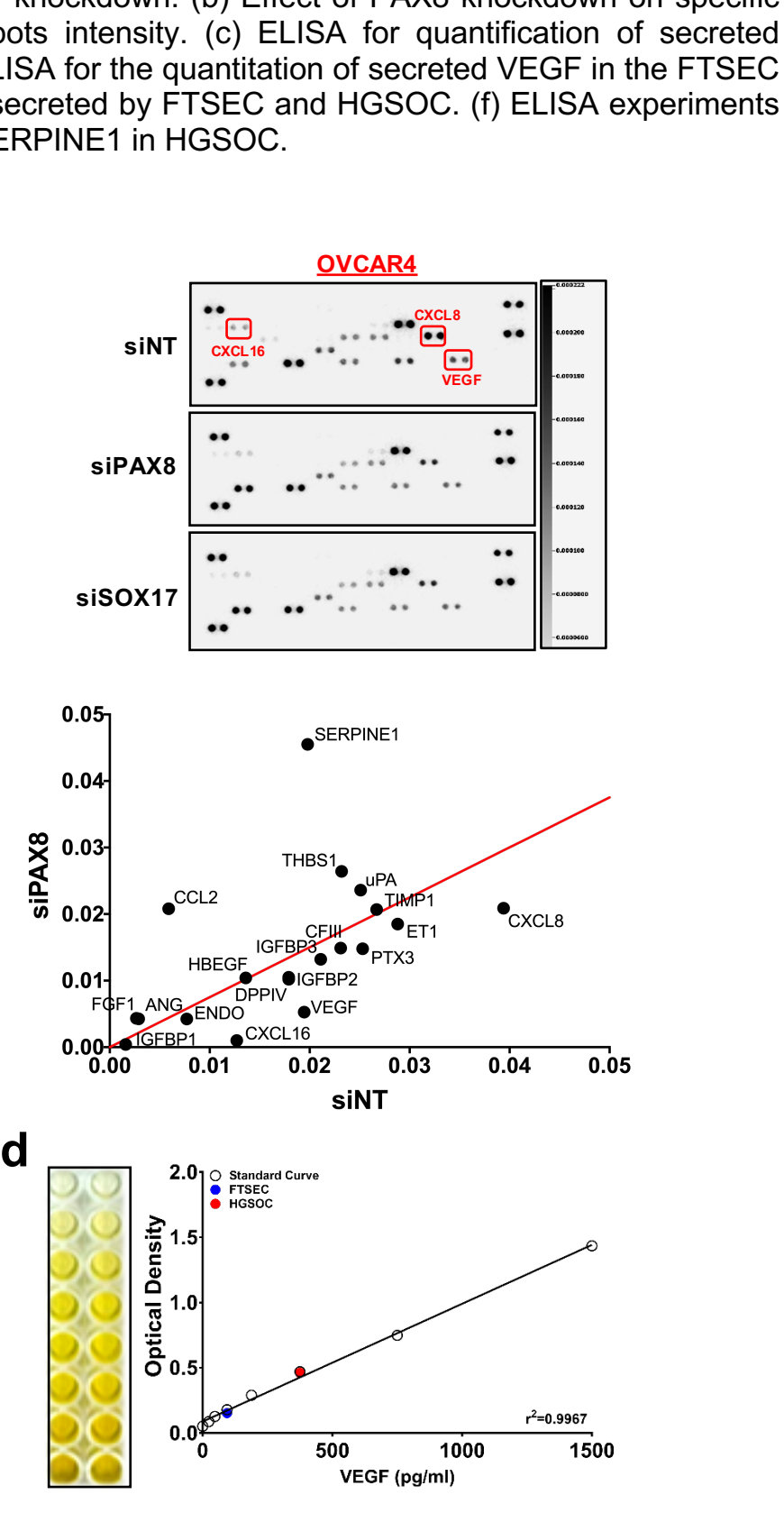

f media from FTSEC and HGSOC cells following PAX8 or SOX17 knockdown. (b) Effect of PAX8 knockdown on specific analytes was produced by quantifying the array membrane spots intensity. (c) ELISA for quantification of secreted SERPINE1 in the FTSEC- and HGSOC-conditioned media. (d) ELISA for he quantitation for queted VEGF in the FTSEC and HGSOC conditioned media. (e) ELISA showing SERPINE1 secreted by FTSEC and HGSOC. (f) ELISA experiments showing the effects of PAX8 or SOX17 knockdown on levels of SERPINE1 in HGSOC. 
Figure 6: PAX8 and SOX17 promote ovarian cancer angiogenesis. (a) Endothelial cells tube formation assay. Representative images depict negative control, VEGF, SERPINE1, FTSEC, and HGSOC conditioned media after PAX8 or SOX17 knockdown. (b) Quantitation of the HUVEC neo-vessels loops. (c) Neovascularization in angioreactors containing conditioned media from HGSOC cells, but not from FTSEC after implantation in nude mice. (d) Quantitation of endothelial cell invasion into angioreactors.
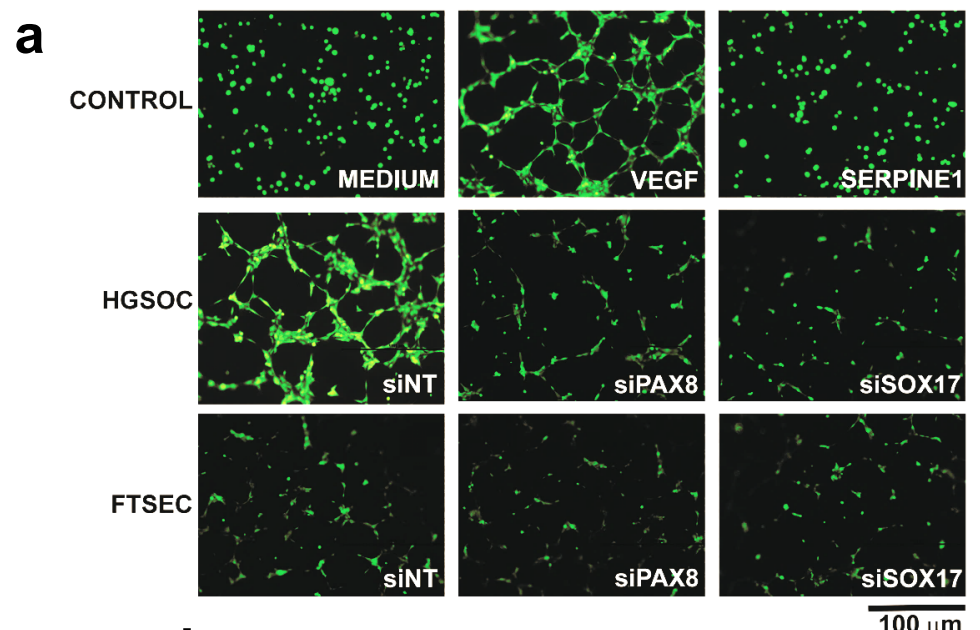

b
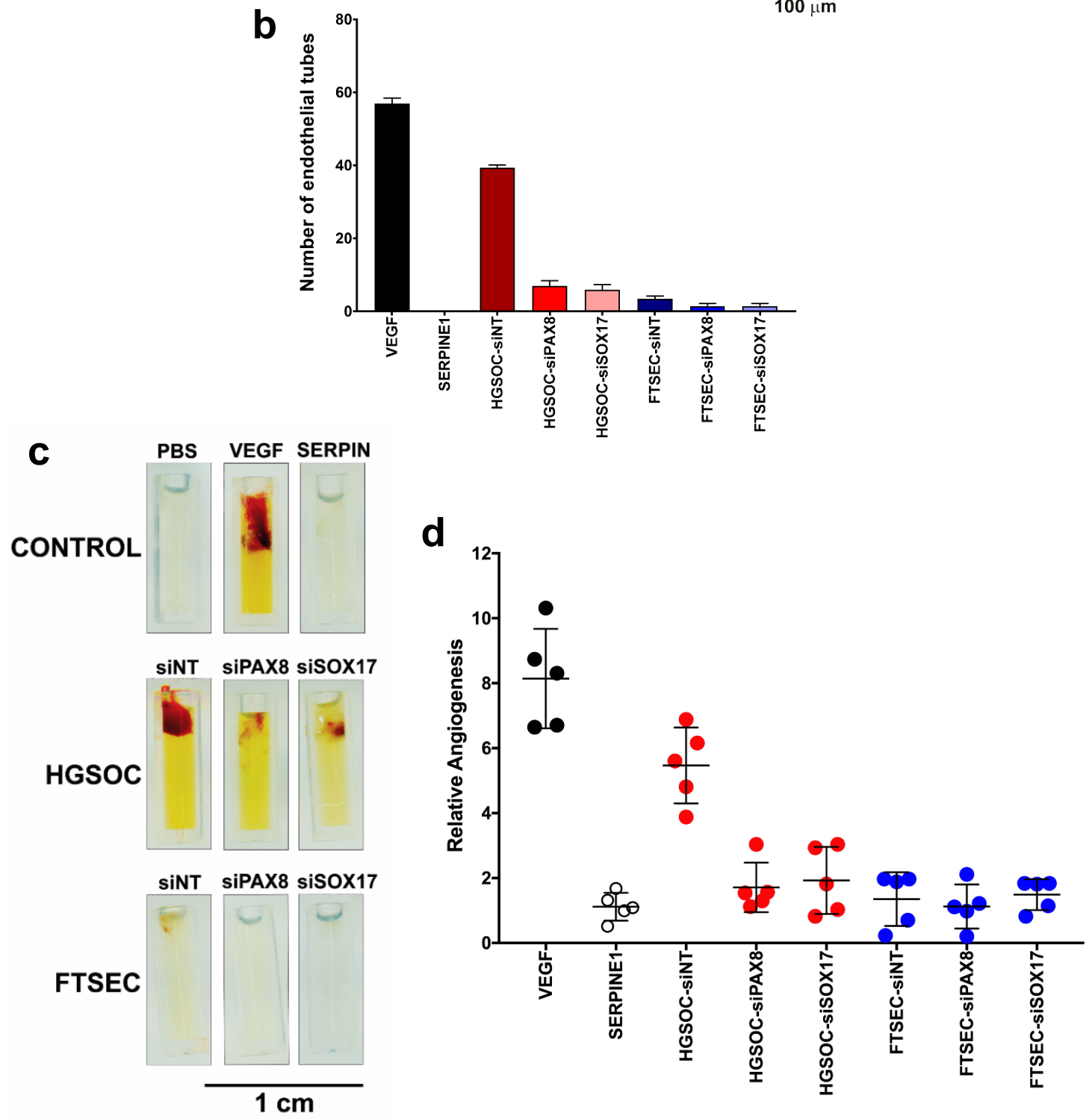
Figure 7: PAX8 or SOX17 doxycycline-inducible knockdown inhibits ovarian cancer progression. (a) Immunoblot of OVTOKO cells harboring inducible shPAX8 or shSOX17 before and after the induction with $1 \mathrm{\mu g} / \mathrm{ml}$ of doxycycline. (b) $/ n$ vivo imaging of OVTOKO tumors in NSG female mice. Animals were imaged after two weeks of doxycycline supplementation. (c) Necropsy of animals depicting ascites and tumors (white arrow) only in the non-targeting control group. (d) The volume of ascites collected from mice after two weeks of doxycycline supplementation. (e) NSG mice reproductive system depicting ovarian cancer volume.

a

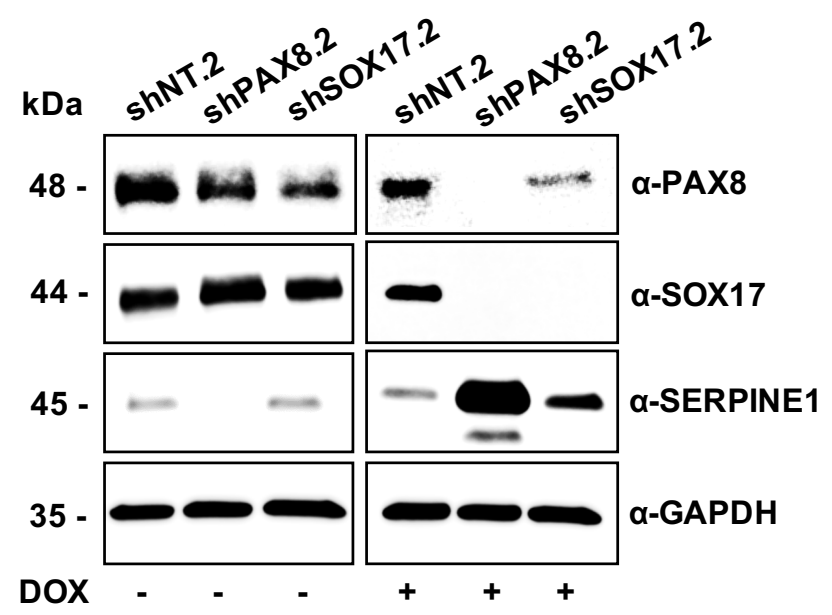

b

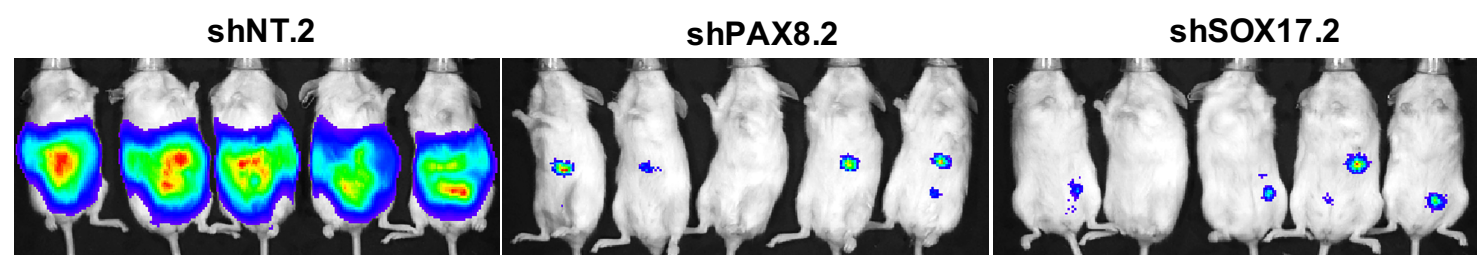

C

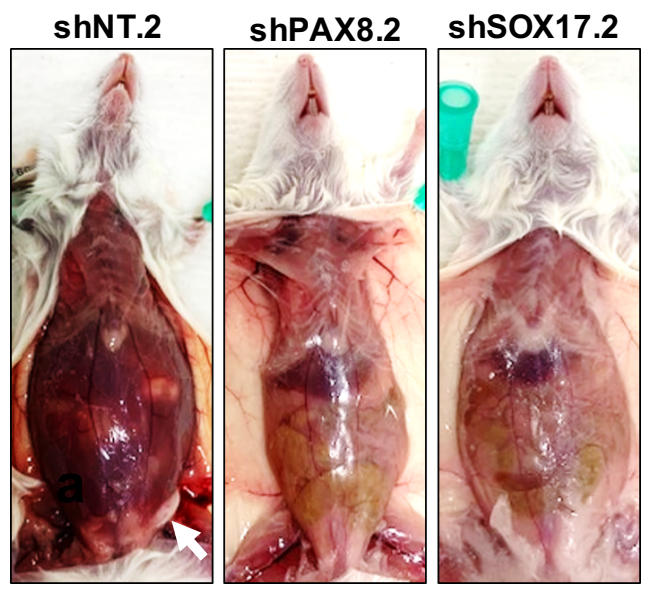

d

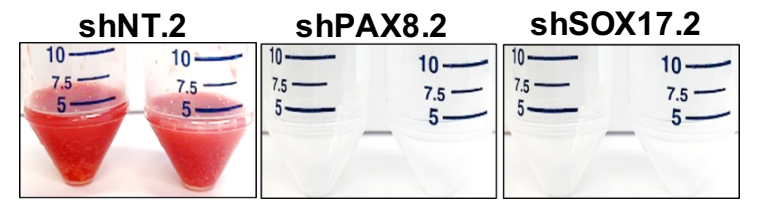

e

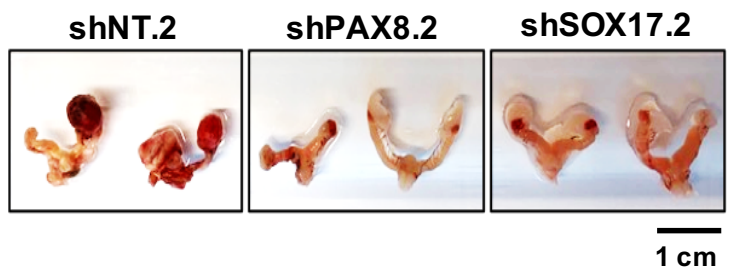




\section{SUPPLEMENTAL INFORMATION}

SI 1: PAX8 and SOX17 have a strong correlation and dependency on ovarian cancer. (a) TCGA ovarian cancer Pearson correlation of PAX8 with the newly identified PAX8-interacting partners. (b) SOX17 has the strongest correlation with PAX8 in ovarian cancer. (c) Ovarian carcinoma cells PAX8 dependency. (d) Ovarian carcinoma cells SOX17 dependency and (e) Ovarian carcinoma cells PAX8-SOX17 co-dependency.

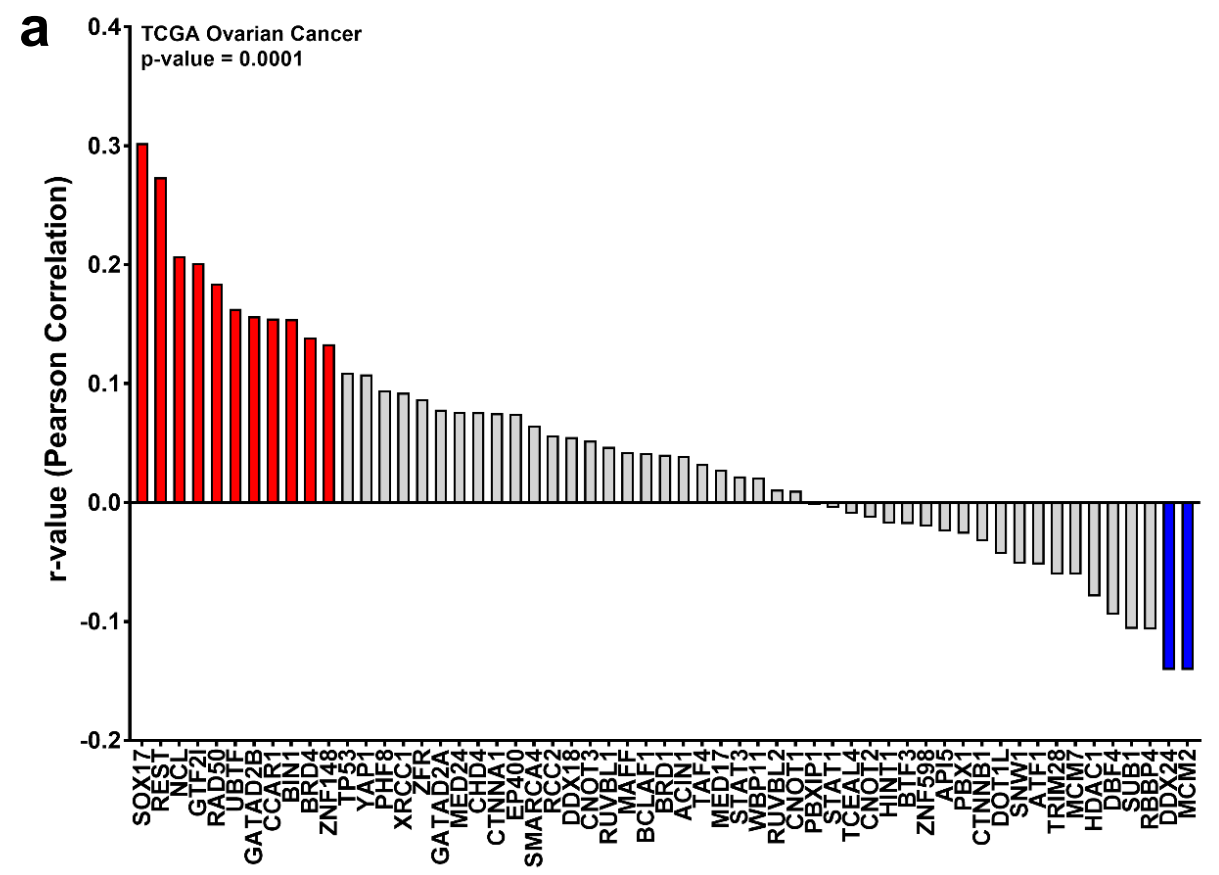

b

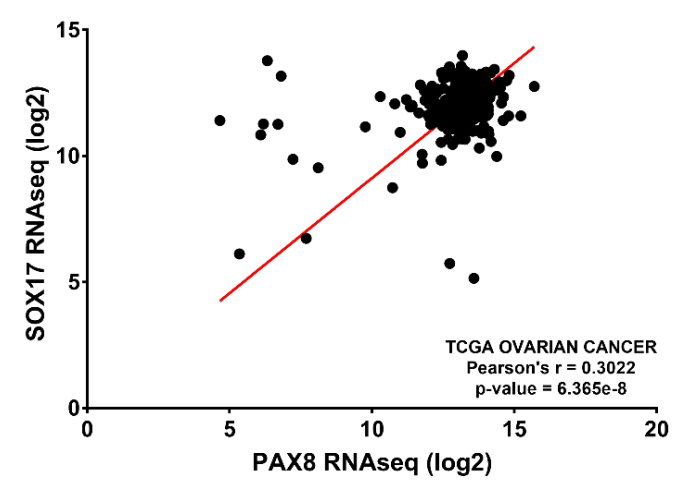

d

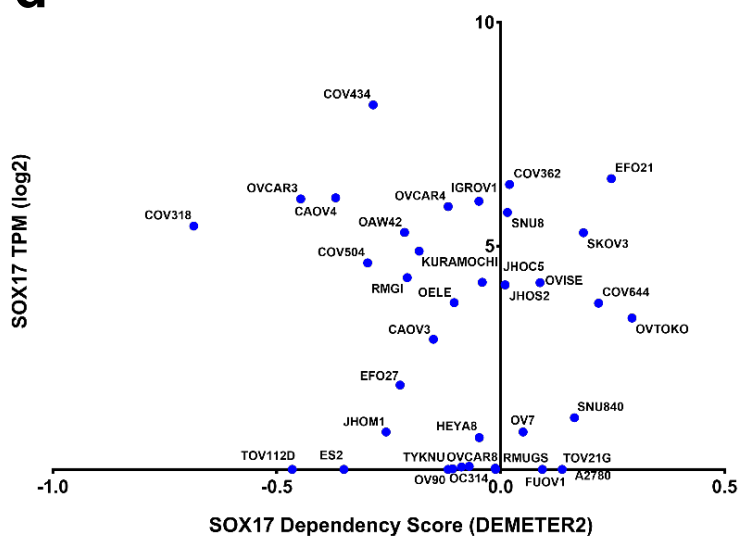

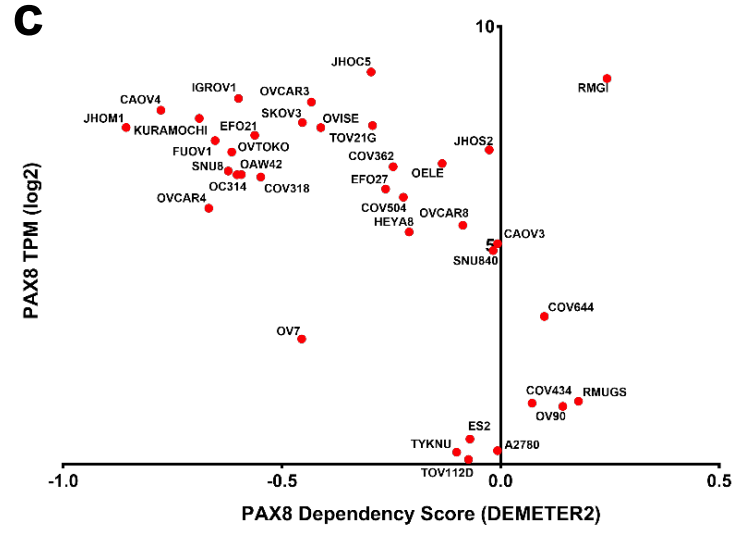

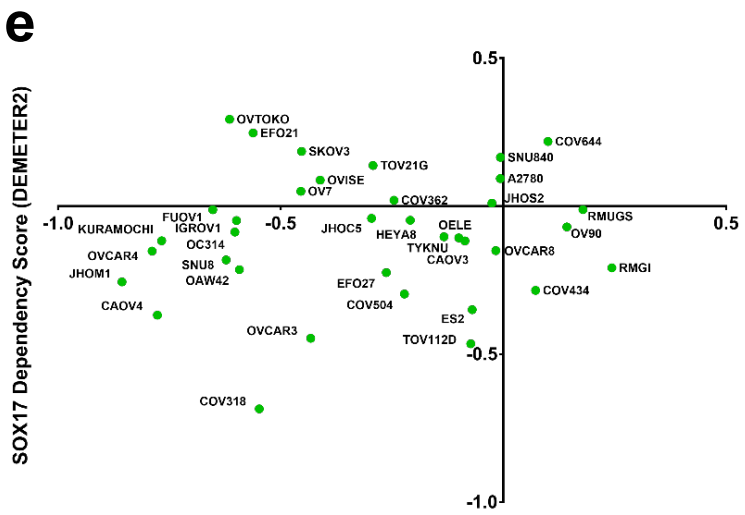

PAX8 Dependency Score (DEMETER2) 
SI 2: Overexpression of PAX8 and SOX17 in ovarian carcinoma cases. (a) Higher expression of PAX8 in ovarian cancer samples. (b) Differential expression of SOX17 in ovarian cancer samples. (c) Most of the TCGA ovarian cancer samples have high PAX8 and SOX17 co-expression. (d) Higher number of PAX8-SOX17 interactions on ovarian cancer cell lines.

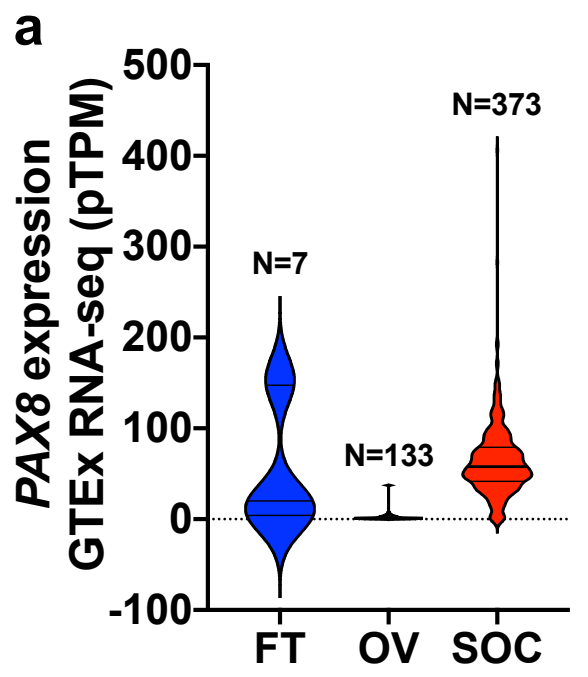

b
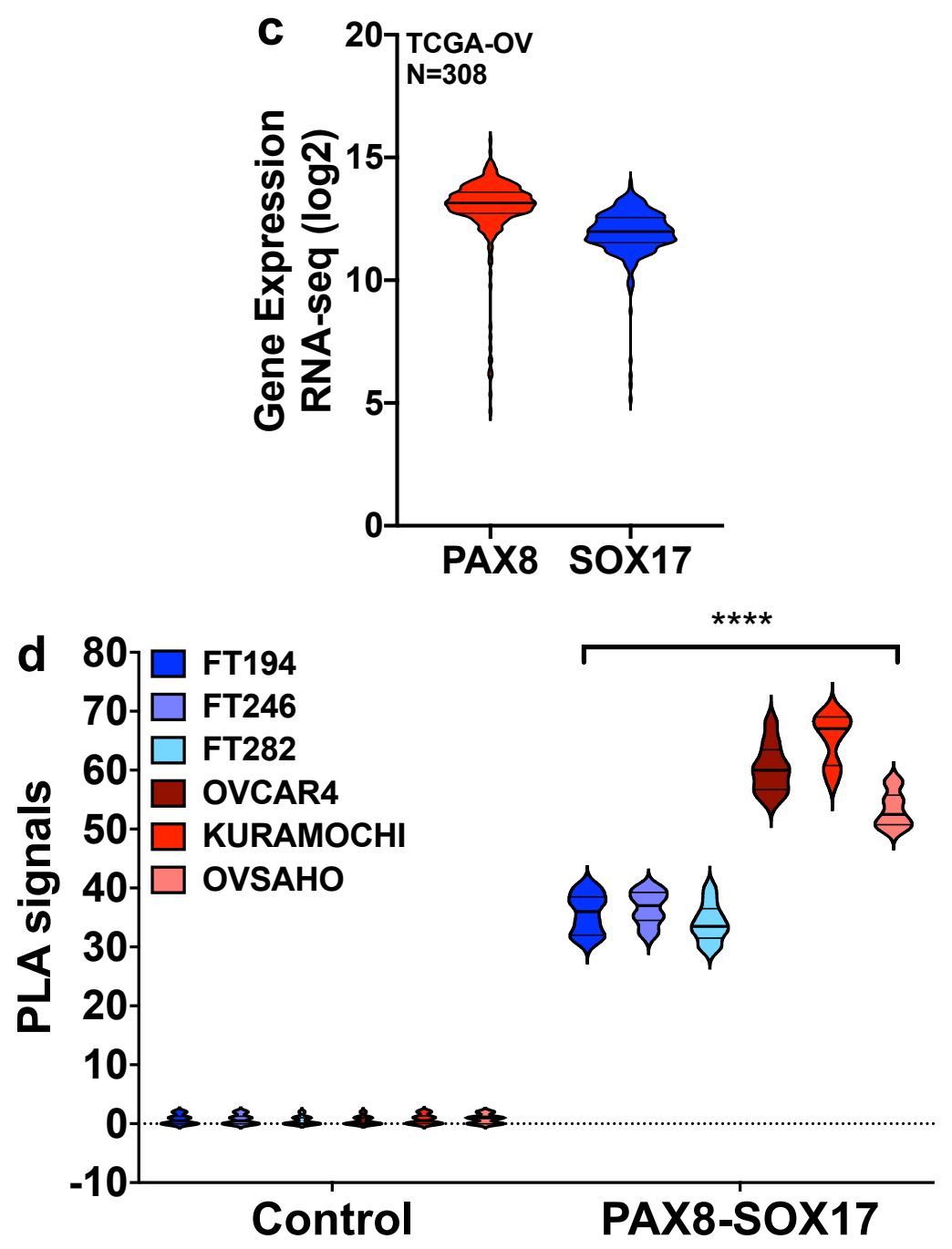
SI 3: PAX8-SOX17 expression co-regulation. (a-b) Immunoblot of four deconvoluted siPAX8 and four deconvoluted siSOX17 knockdowns on FTSEC and HGSOC cell lines. (c-d) PAX8 and SOX17 protein levels after knockdowns with four pooled siPAX8, four pooled siSOX17 or then all combined by reverse-phase protein array.

a

$\underline{\text { FT194 }}$
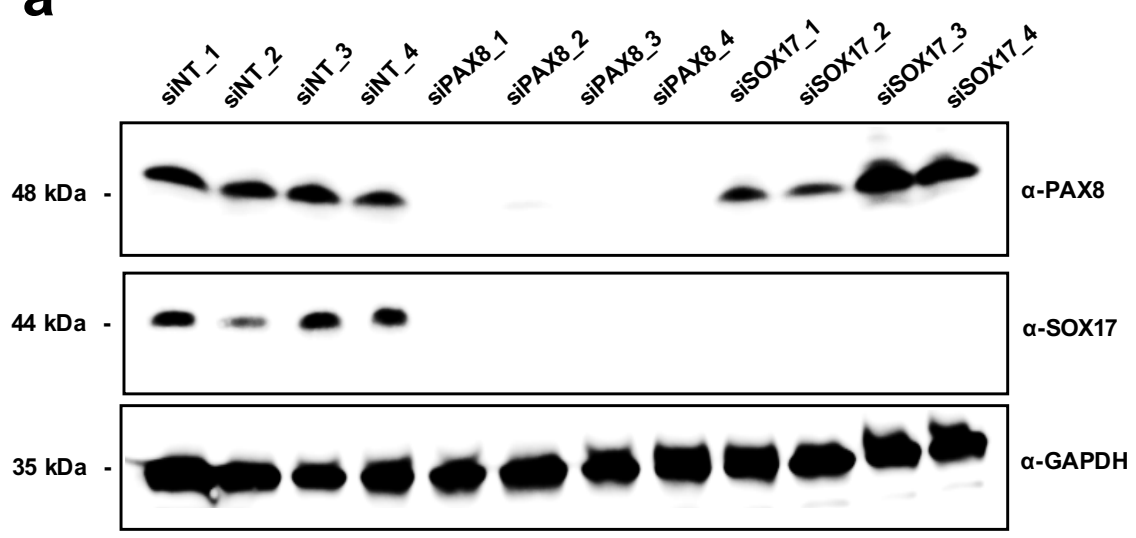

C

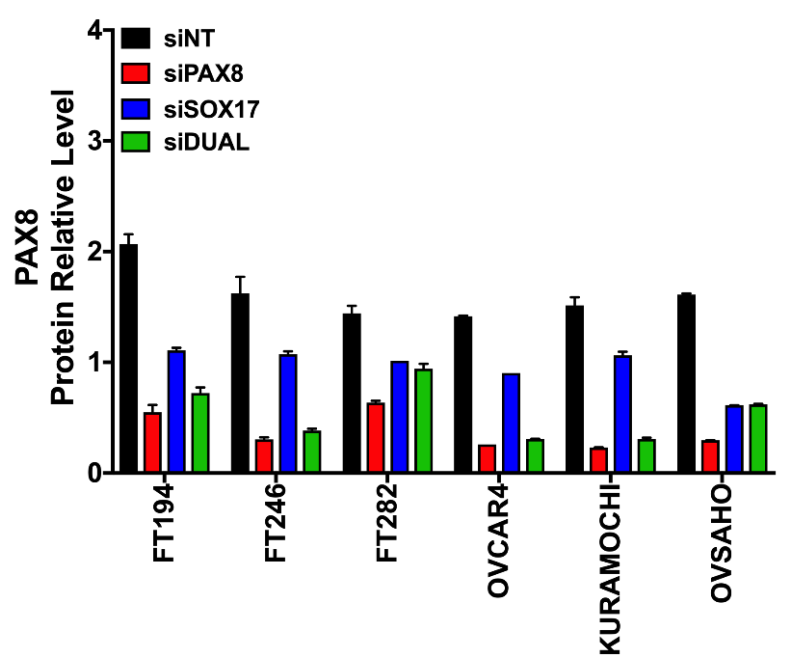

b

OVCAR4
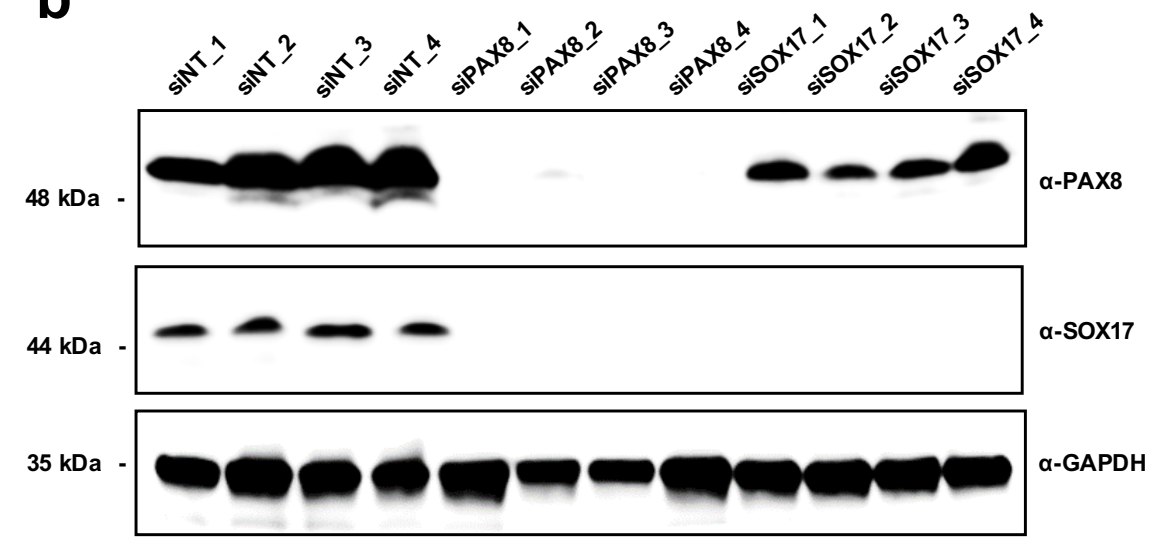
SI 4: PAX8-SOX17 tightly suppresses SERPINE1 expression. (a) RNA-seq analysis depicting SERPINE1 gene upregulation after PAX8, SOX17 or DUAL knockdown. (b) SERPINE1 average expression after PAX8, SOX17 or DUAL knockdown. (c) RPPA ontology analysis corroborating enrichment of angiogenesis and VEGF pathways. (d) SERPINE1 relative protein levels in different FTSEC lines and HGSOC lines, depicting suppression of SERPINE1 during malignant transformation. (e) Immunoblot of different benign and malignant cell lines showing drastically reduction of SERPINE1 levels in cell lines with increased SOX17 expression.
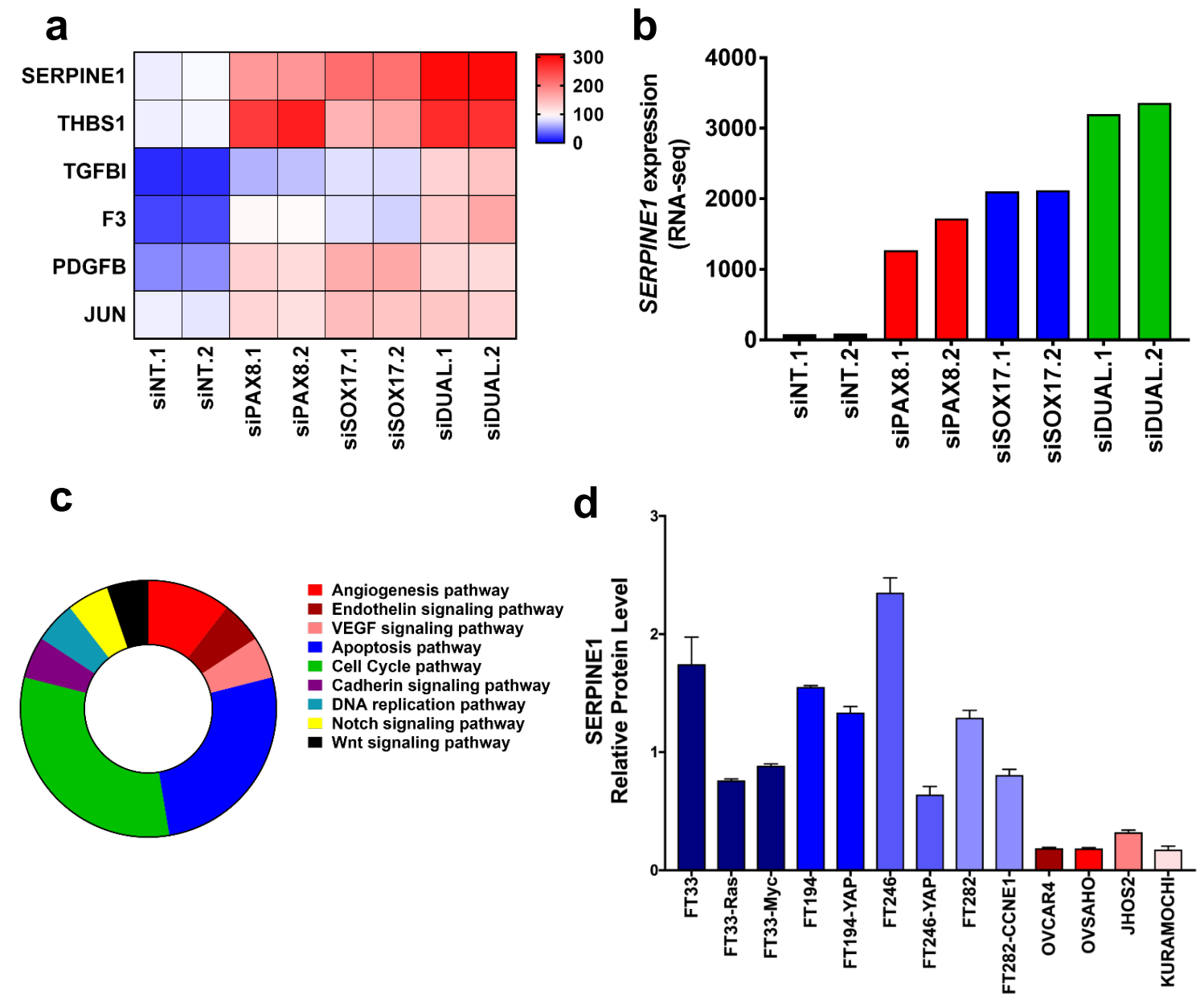

e

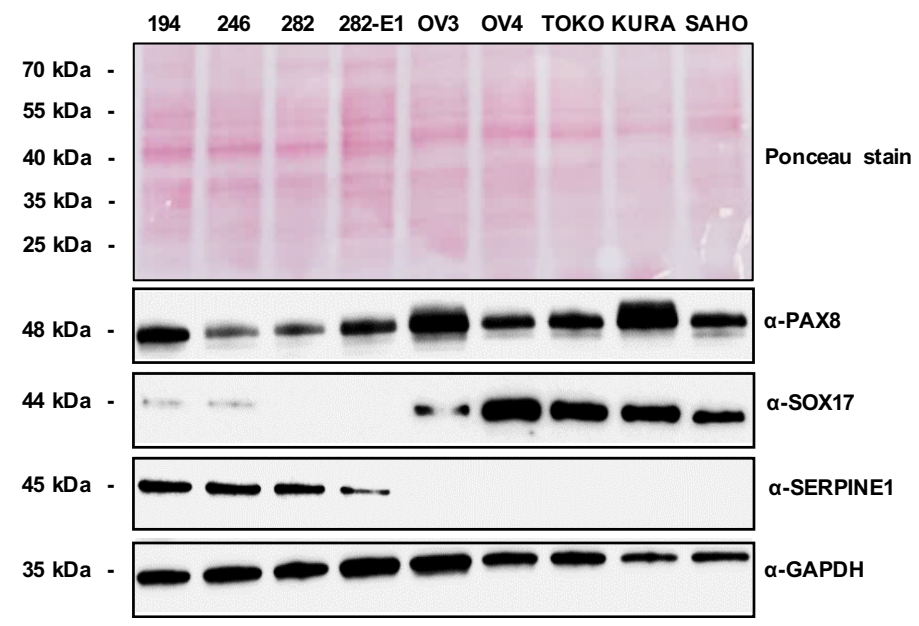


SI 5: PAX8 and SOX17 regulate the secretion of angiogenesis mediators. (a) Human angiogenesis arrays of fresh DMEM/F12 and RMPI media with no detection of angiogenesis mediators, negative controls. (b-c-d) Human angiogenesis array of additional three fallopian tube secretory cells and additional three ovarian carcinoma cells conditioned media after PAX8 or SOX17 knockdown.

a

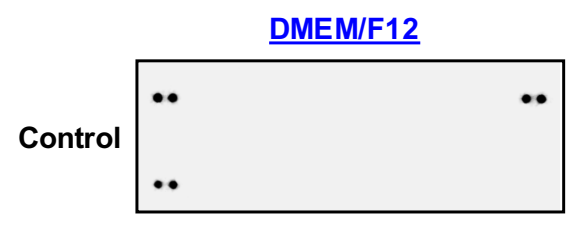

b

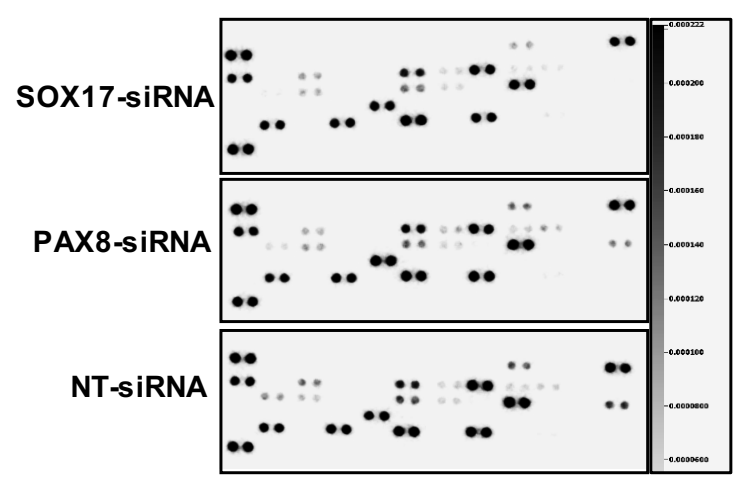

C

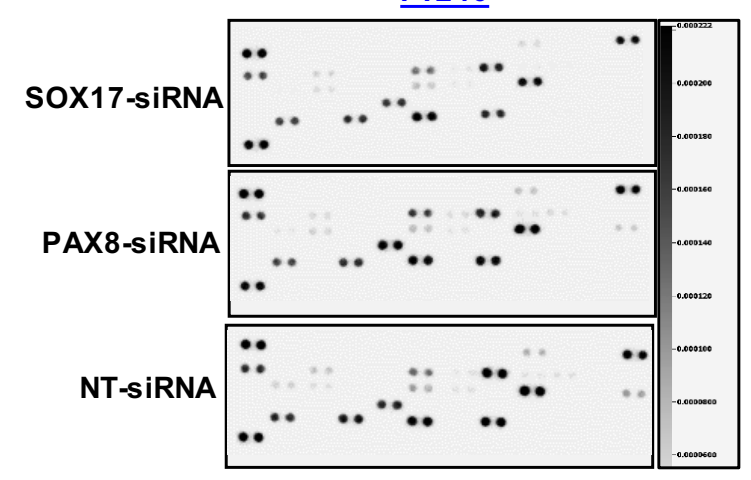

d

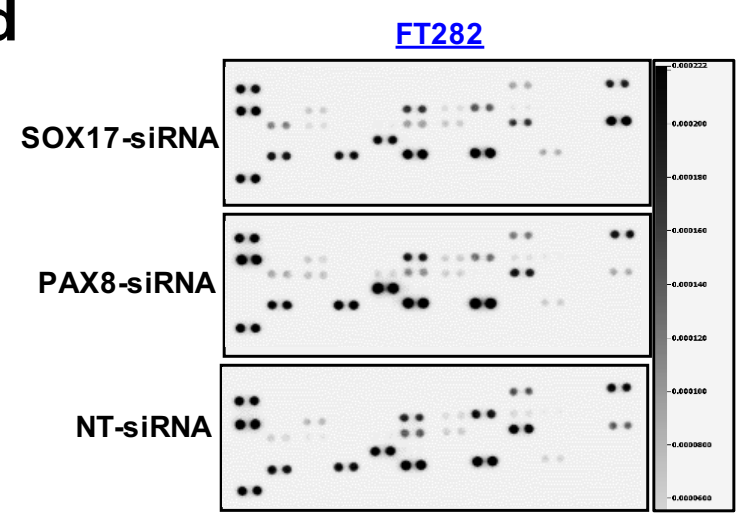

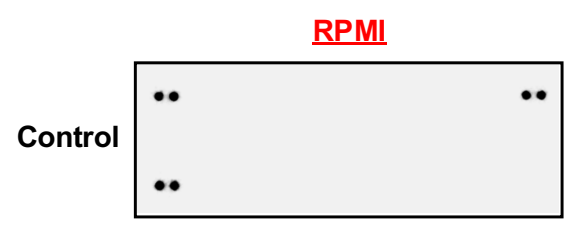
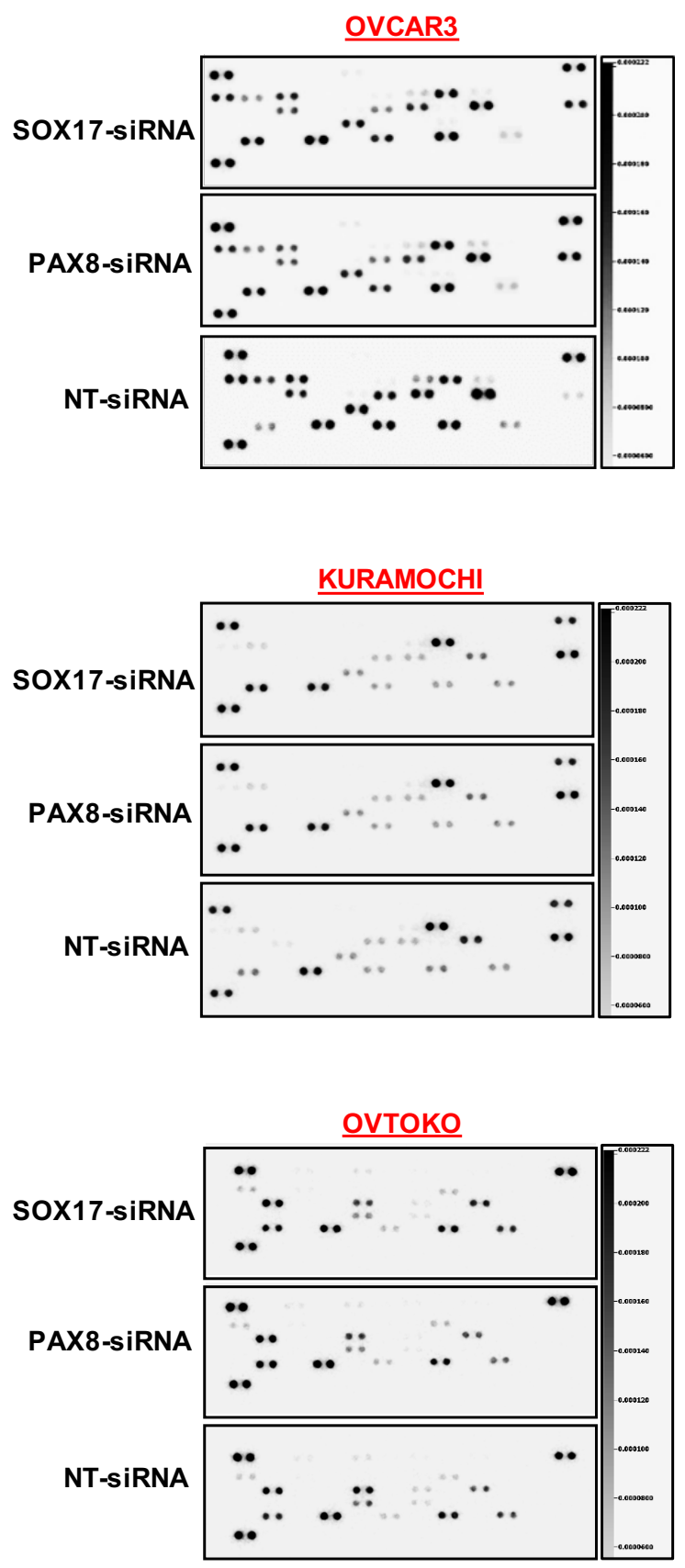
SI 6: PAX8-SOX17 regulates angiogenesis through the PLCy1 pathway. (a) Schematic illustration of the PLCy1 pathway. (b) RPPA analysis showing up-regulation of VEGFR2 protein levels followed PAX8 and SOX17 knockdown. (c) RPPA analysis showing reduced phosphorylated-PLCy1 and phosphorylated-ERK1/2 (active molecules) followed PAX8 and SOX17 knockdown. (d) Confirmation by western blot of the PLCy1 pathway inactivation.

a

(1)

(1)

8

9

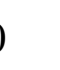

2

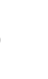

4

a

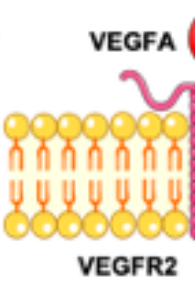

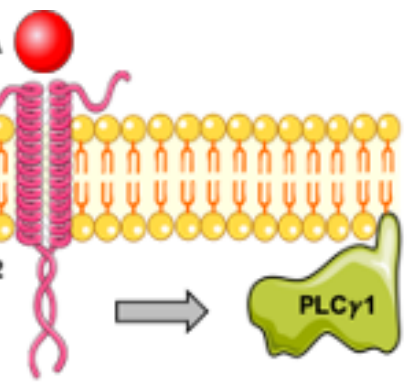

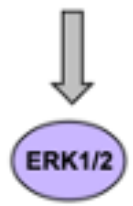

\section{Angiogenesis}

\section{C}
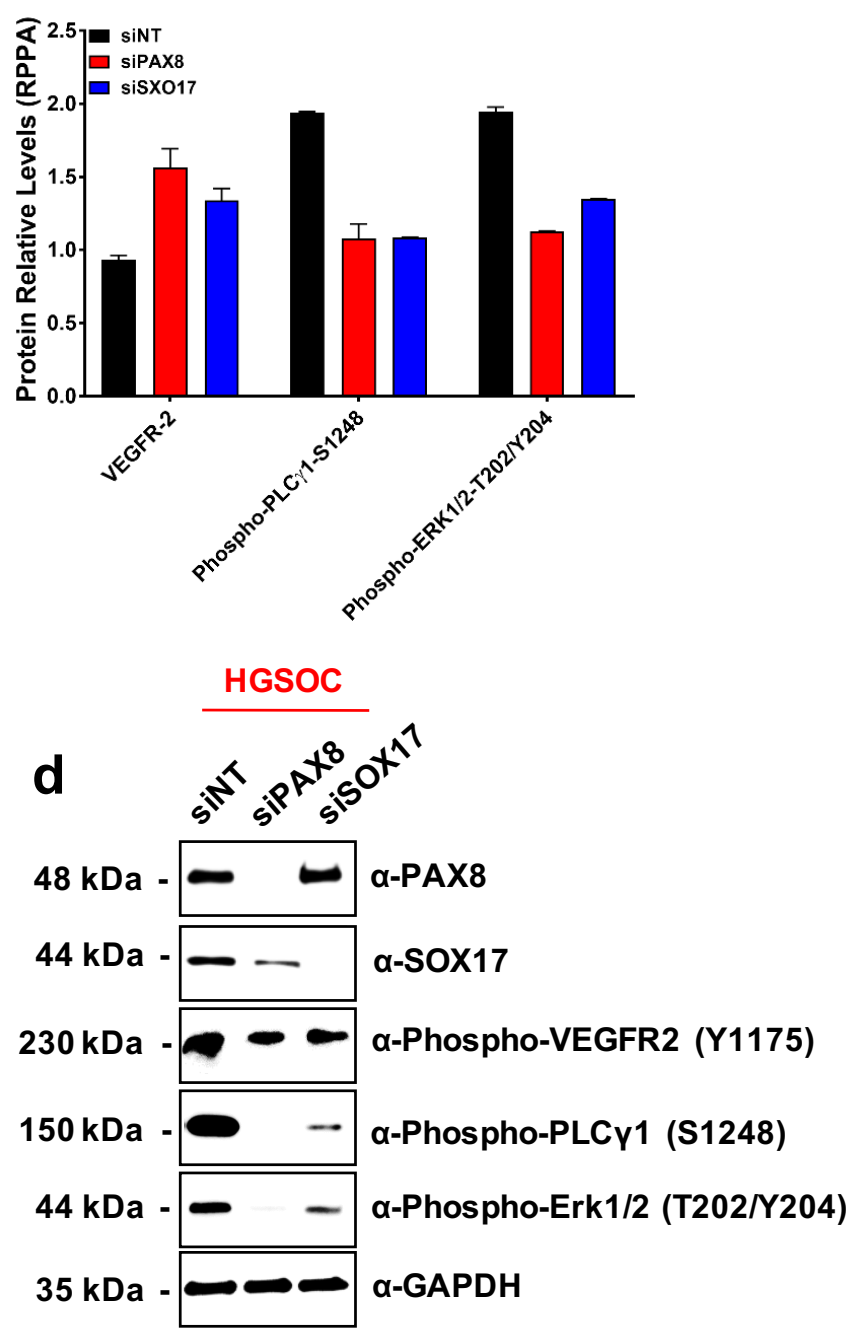

b

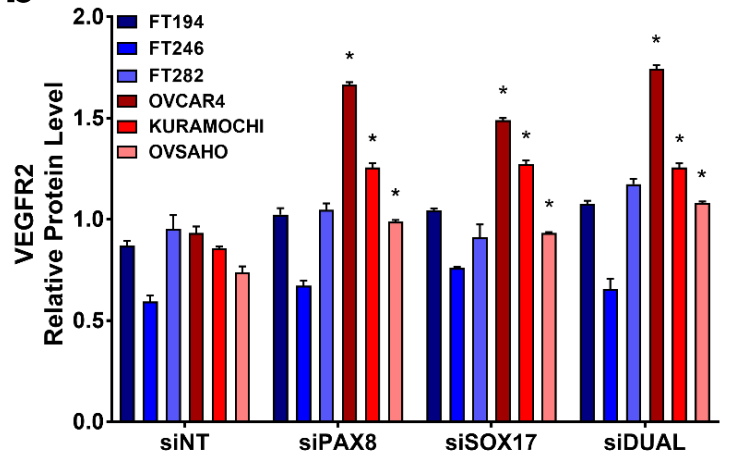


SI 7: PAX8-SOX17 suppress anti-angiogenesis factors. (a) Spearman correlation analysis of TCGA ovarian cancer data set depicting negative inversely correlation between SOX17 and angiogenesis inhibitors (SERPINE1 and THBS1). (b) Schematic diagram of the activation of tumor angiogenesis by PAX8 and SOX17 expression.

a

\begin{tabular}{|c|c|c|}
\hline TCGA-OVARIAN & $\begin{array}{c}\text { SOX17 } \\
\text { vs. } \\
\text { SERPINE1 }\end{array}$ & $\begin{array}{l}\text { SOX17 } \\
\text { vs. } \\
\text { THBS1 }\end{array}$ \\
\hline Spearman $r$ & -0.3222 & -0.2936 \\
\hline $95 \%$ confidence interval & -0.4216 to -0.2152 & -0.3952 to -0.1848 \\
\hline \multicolumn{3}{|l|}{ P value } \\
\hline$P$ (two-tailed) & $<0.0001$ & $<0.0001$ \\
\hline$P$ value summary & $* * * *$ & $* * * *$ \\
\hline $\begin{array}{l}\text { Significant? } \\
\text { (alpha }=0.05)\end{array}$ & Yes & Yes \\
\hline Number of XY Pairs & 308 & 308 \\
\hline
\end{tabular}

b

Pro-angiogenesis

Anti-angiogenesis

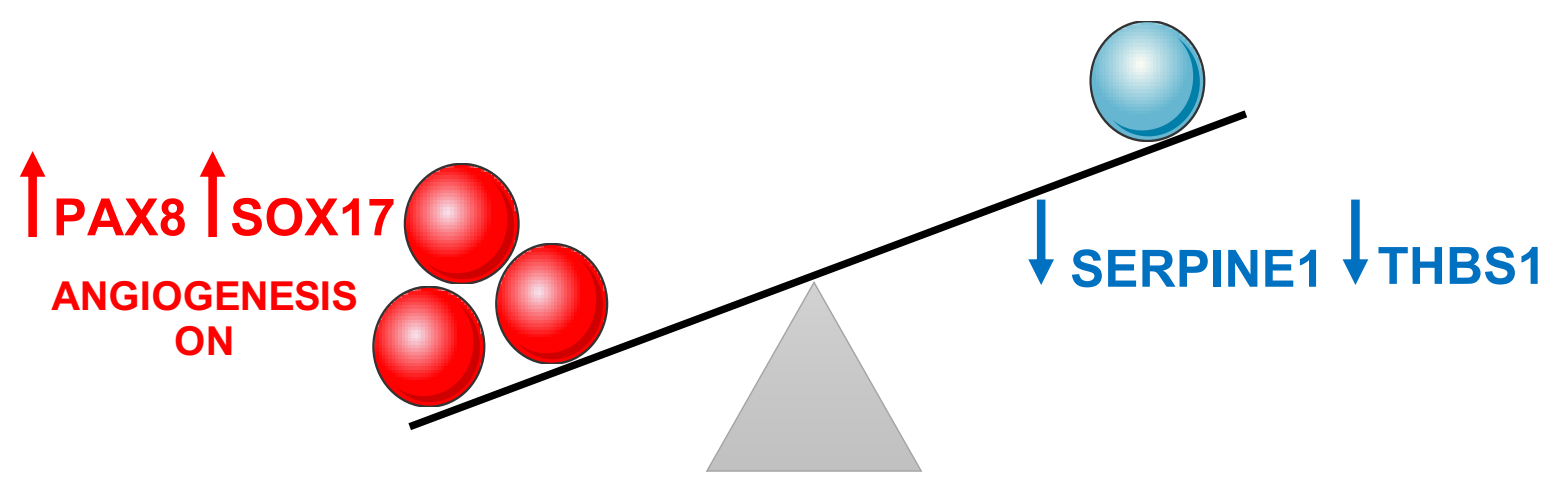


bioRxiv preprint doi: https://doi.org/10.1101/2020.09.09.290387; this version posted September 10, 2020 . The copyright holder for this preprint

(which was not certified by peer review) is the author/funder, who has granted bioRxiv a license to display the preprint in perpetuity. It is made available under aCC-BY-NC-ND 4.0 International license.

98 TABLES

Table 1: Putative PAX8-interacting partners.

\begin{tabular}{|c|c|c|c|c|c|c|c|}
\hline \multirow[b]{2}{*}{$\begin{array}{l}\text { UniProtKB } \\
\text { Accession } \\
\text { no. }\end{array}$} & \multirow[b]{2}{*}{$\begin{array}{l}\text { Spot } \\
\text { name }\end{array}$} & \multirow[b]{2}{*}{ Description } & \multirow[b]{2}{*}{$\begin{array}{l}\text { Theoretical } \\
\text { mass } \\
\text { (kDa) }\end{array}$} & \multicolumn{3}{|c|}{ MaxQuant search results } & \multirow[b]{2}{*}{$\begin{array}{c}\text { Fold } \\
\text { change } \\
\text { Cancer } \\
\text { vs. } \\
\text { Normal }^{\#}\end{array}$} \\
\hline & & & & $\begin{array}{l}\text { No. of } \\
\text { matched } \\
\text { peptides }\end{array}$ & $\begin{array}{l}\text { Sequence } \\
\text { coverage } \\
(\%)\end{array}$ & Score & \\
\hline \multicolumn{8}{|c|}{ TRANSCRIPTION FACTORS AND REGULATORS } \\
\hline Q06710 & PAX8 & $\begin{array}{l}\text { Paired box protein PAX- } \\
8\end{array}$ & 48.2 & 13 & 33.8 & 162.9 & +1.38 \\
\hline Q13263 & TRIM28 & $\begin{array}{l}\text { Transcription } \\
\text { intermediary factor } 1 \text { - } \\
\text { beta }\end{array}$ & 88.5 & 5 & 11.3 & 79.4 & -0.22 \\
\hline Q1MSW8 & TP53 & $\begin{array}{l}\text { Cellular tumor antigen } \\
\text { p53 }\end{array}$ & 50.2 & 4 & 22.2 & 76.1 & +2.79 \\
\hline Q9H6I2 & SOX17 & $\begin{array}{l}\text { Transcription factor } \\
\text { SOX-17 }\end{array}$ & 44.3 & 3 & 11.1 & 74.8 & +1.05 \\
\hline P78347 & GTF2I & $\begin{array}{l}\text { General transcription } \\
\text { factor III }\end{array}$ & 107.9 & 19 & 11.3 & 73.3 & +1.06 \\
\hline Q86YP4 & GATAD2A & $\begin{array}{l}\text { Transcriptional } \\
\text { repressor p66-alpha }\end{array}$ & 68.1 & 7 & 9.6 & 45.1 & -0.66 \\
\hline P40763 & STAT3 & $\begin{array}{l}\text { Signal transducer and } \\
\text { activator of transcription } \\
3\end{array}$ & 76.1 & 8 & 3.9 & 39.6 & +0.01 \\
\hline A5YKK6 & CNOT1 & $\begin{array}{l}\text { CCR4-NOT } \\
\text { transcription complex } \\
\text { subunit } 1\end{array}$ & 266.4 & 6 & 2.5 & 38.1 & -1.13 \\
\hline P17480 & UBTF & $\begin{array}{l}\text { Nucleolar transcription } \\
\text { factor } 1\end{array}$ & 75.9 & 10 & 6.3 & 31.6 & -0.96 \\
\hline P51532 & SMARCA4 & $\begin{array}{l}\text { Transcription activator } \\
\text { BRG1 }\end{array}$ & 184.6 & 15 & 3.9 & 28.8 & -0.18 \\
\hline O00268 & TAF4 & $\begin{array}{l}\text { Transcription initiation } \\
\text { factor TFIID subunit } 4\end{array}$ & 50.2 & 3 & 6.8 & 20.4 & +0.70 \\
\hline 060885 & BRD4 & $\begin{array}{l}\text { Bromodomain- } \\
\text { containing protein } 4\end{array}$ & 152.2 & 3 & 2.5 & 18.7 & -2.08 \\
\hline Q13573 & SNW1 & $\begin{array}{l}\text { SNW domain- } \\
\text { containing protein } 1\end{array}$ & 43.3 & 3 & 9.9 & 18.1 & +1.57 \\
\hline 075448 & MED24 & $\begin{array}{l}\text { Mediator of RNA } \\
\text { polymerase II } \\
\text { transcription subunit } 24\end{array}$ & 91.3 & 3 & 4.6 & 17.8 & -0.79 \\
\hline Q9NZN8 & CNOT2 & $\begin{array}{l}\text { CCR4-NOT } \\
\text { transcription complex } \\
\text { subunit } 2\end{array}$ & 29.9 & 2 & 9.1 & 16.7 & -0.97 \\
\hline P20290 & BTF3 & $\begin{array}{l}\text { Transcription factor } \\
\text { BTF3 }\end{array}$ & 17.7 & 2 & 17.3 & 14.6 & +2.02 \\
\hline A0A0U1RRM1 & GATAD2B & $\begin{array}{l}\text { Transcriptional } \\
\text { repressor p66-beta }\end{array}$ & 63.4 & 4 & 5.9 & 14.2 & -0.30 \\
\hline E9PJZ4 & MED17 & $\begin{array}{l}\text { Mediator of RNA } \\
\text { polymerase II } \\
\text { transcription subunit } 17\end{array}$ & 16.3 & 2 & 16.1 & 13.8 & +1.94 \\
\hline Q96EI5 & TCEAL4 & $\begin{array}{l}\text { Transcription elongation } \\
\text { factor A protein-like } 4\end{array}$ & 21.5 & 5 & 11.8 & 12.5 & 0.00 \\
\hline H3BQQ2 & ZNF598 & Zinc finger protein 598 & 93.3 & 4 & 1.5 & 12.5 & +0.34 \\
\hline
\end{tabular}


bioRxiv preprint doi: https://doi.org/10.1101/2020.09.09.290387; this version posted September $10,2020$. The copyright holder for this preprint (which was not certified by peer review) is the author/funder, who has granted bioRxiv a license to display the preprint in perpetuity. It is made available under aCC-BY-NC-ND 4.0 International license.

\begin{tabular}{|c|c|c|c|c|c|c|c|}
\hline Q9NYF8 & BCLAF1 & $\begin{array}{l}\text { Bcl-2-associated } \\
\text { transcription factor } 1\end{array}$ & 52.9 & 11 & 5.4 & 12.2 & -0.23 \\
\hline 075175 & CNOT3 & $\begin{array}{l}\text { CCR4-NOT } \\
\text { transcription complex } \\
\text { subunit } 3\end{array}$ & 31.2 & 8 & 16.3 & 10.9 & -4.48 \\
\hline Q4FD37 & ZNF148 & Zinc finger protein 148 & 74.5 & 4 & 1.2 & 9.2 & 0.00 \\
\hline Q96AQ6 & PBXIP1 & $\begin{array}{l}\text { Pre-B-cell leukemia } \\
\text { transcription factor- } \\
\text { interacting protein } 1\end{array}$ & 57.5 & 6 & 2.2 & 8.5 & +0.65 \\
\hline P42224 & STAT1 & $\begin{array}{l}\text { Signal transducer and } \\
\text { activator of transcription } \\
\text { 1-alpha/beta }\end{array}$ & 88.3 & 3 & 1.7 & 8.1 & -0.93 \\
\hline Q9ULX9 & MAFF & $\begin{array}{l}\text { Transcription factor } \\
\text { MafF }\end{array}$ & 14.5 & 2 & 11.9 & 7.5 & 0.00 \\
\hline Q13127 & REST & $\begin{array}{l}\text { RE1-silencing } \\
\text { transcription factor }\end{array}$ & 52.2 & 3 & 2.1 & 7.3 & +1.02 \\
\hline P46937 & YAP1 & $\begin{array}{l}\text { Transcriptional } \\
\text { coactivator YAP1 }\end{array}$ & 18.7 & 9 & 6.5 & 6.6 & +1.27 \\
\hline P53999 & SUB1 & $\begin{array}{l}\text { Activated RNA } \\
\text { polymerase II } \\
\text { transcriptional } \\
\text { coactivator p15 }\end{array}$ & 14.4 & 3 & 18.9 & 6.4 & +1.90 \\
\hline P40424 & PBX1 & $\begin{array}{l}\text { Pre-B-cell leukemia } \\
\text { transcription factor } 1\end{array}$ & 46.6 & 1 & 10.3 & 5.8 & +0.78 \\
\hline P18846 & ATF1 & $\begin{array}{l}\text { Cyclic AMP-dependent } \\
\text { transcription factor ATF- } \\
1\end{array}$ & 57.6 & 23 & 5.8 & 2.1 & +0.03 \\
\hline \multicolumn{8}{|c|}{ RNA PROCESSING } \\
\hline Q9BQ02 & NCL & Nucleolin & 76.6 & 11 & 30.1 & 188.9 & -0.63 \\
\hline A8K849 & ZFR & $\begin{array}{l}\text { Zinc finger RNA-binding } \\
\text { protein }\end{array}$ & 66.3 & 3 & 7.1 & 16.6 & +0.41 \\
\hline Q9NVP1 & DDX18 & $\begin{array}{l}\text { ATP-dependent RNA } \\
\text { helicase DDX18 }\end{array}$ & 61.6 & 4 & 4.4 & 13.9 & +2.24 \\
\hline Q59FS7 & DDX24 & $\begin{array}{l}\text { ATP-dependent RNA } \\
\text { helicase DDX24 }\end{array}$ & 75.1 & 1 & 1.6 & 8.4 & +5.29 \\
\hline Q9Y2W2 & WBP11 & $\begin{array}{l}\text { WW domain-binding } \\
\text { protein } 11\end{array}$ & 64.9 & 1 & 2.4 & 7.2 & +0.93 \\
\hline \multicolumn{8}{|c|}{ DNA PROCESSING } \\
\hline P33993 & MCM7 & $\begin{array}{l}\text { DNA replication } \\
\text { licensing factor } \mathrm{MCM} 7\end{array}$ & 81.2 & 11 & 23.8 & 114.6 & +0.35 \\
\hline Q92878 & RAD50 & $\begin{array}{l}\text { DNA repair protein } \\
\text { RAD50 }\end{array}$ & 138.4 & 12 & 11.5 & 85.4 & +0.49 \\
\hline Q9Y265 & RUVBL1 & RuvB-like 1 & 50.2 & 8 & 25.4 & 76.1 & +1.46 \\
\hline Q14839 & CHD4 & $\begin{array}{l}\text { Chromodomain- } \\
\text { helicase-DNA-binding } \\
\text { protein } 4\end{array}$ & 215.2 & 15 & 3.6 & 45.8 & +0.18 \\
\hline Q9P258 & RCC2 & Protein RCC2 & 56.1 & 5 & 14.2 & 43.2 & +1.53 \\
\hline Q9Y230 & RUVBL2 & RuvB-like 2 & 51.1 & 9 & 13.2 & 35.4 & +0.84 \\
\hline P49736 & MCM2 & $\begin{array}{l}\text { DNA replication } \\
\text { licensing factor } \mathrm{MCM} 2\end{array}$ & 87.4 & 6 & 6.1 & 26.2 & -0.09 \\
\hline P18887 & XRCC1 & $\begin{array}{l}\text { DNA repair protein } \\
\text { XRCC1 }\end{array}$ & 42.8 & 2 & 5.8 & 13.5 & -1.03 \\
\hline B7Z8C6 & DBF4 & $\begin{array}{l}\text { Protein DBF4 homolog } \\
\text { A }\end{array}$ & 51.8 & 2 & 3.1 & 6.5 & +1.75 \\
\hline \multicolumn{8}{|c|}{ EPIGENETIC REGULATORS } \\
\hline Q09028 & RBBP4 & $\begin{array}{l}\text { Histone-binding protein } \\
\text { RBBP4 }\end{array}$ & 46.9 & 4 & 7.9 & 27.9 & -2.96 \\
\hline
\end{tabular}


bioRxiv preprint doi: https://doi.org/10.1101/2020.09.09.290387; this version posted September $10,2020$. The copyright holder for this preprint (which was not certified by peer review) is the author/funder, who has granted bioRxiv a license to display the preprint in perpetuity. It is made available under aCC-BY-NC-ND 4.0 International license.

\begin{tabular}{|c|c|c|c|c|c|c|c|}
\hline 094776 & MTA2 & $\begin{array}{l}\text { Metastasis-associated } \\
\text { protein MTA2 }\end{array}$ & 75.0 & 3 & 3 & 12.5 & +0.03 \\
\hline Q6IT96 & HDAC1 & Histone deacetylase & 55.1 & 2 & 4.4 & 11.8 & +1.99 \\
\hline Q96L91 & EP400 & $\begin{array}{l}\text { E1A-binding protein } \\
\text { p400 }\end{array}$ & 335.8 & 1 & 0.6 & 9.4 & +0.31 \\
\hline Q8TEK3 & DOT1L & $\begin{array}{l}\text { Histone-lysine } \mathrm{N}- \\
\text { methyltransferase, H3 } \\
\text { lysine-79 specific }\end{array}$ & 24.1 & 3 & 3.4 & 7.6 & -1.60 \\
\hline Q9UPP1 & PHF8 & $\begin{array}{l}\text { Histone lysine } \\
\text { demethylase PHF8 }\end{array}$ & 33.2 & 1 & 4.5 & 7.2 & -0.27 \\
\hline Q13330 & MTA1 & $\begin{array}{l}\text { Metastasis-associated } \\
\text { protein MTA1 }\end{array}$ & 28.7 & 8 & 5.1 & 6.3 & +1.55 \\
\hline Q59G93 & BRD1 & $\begin{array}{l}\text { Bromodomain- } \\
\text { containing protein } 1\end{array}$ & 53.8 & 1 & 1.9 & 6.2 & +0.30 \\
\hline \multicolumn{8}{|c|}{ APOPTOTIC SIGNALING PATHWAY } \\
\hline Q8N163 & CCAR2 & $\begin{array}{l}\text { Cell cycle and } \\
\text { apoptosis regulator } \\
\text { protein } 2\end{array}$ & 102.9 & 8 & 10.2 & 57.1 & +0.51 \\
\hline Q8IX12 & CCAR1 & $\begin{array}{l}\text { Cell division cycle and } \\
\text { apoptosis regulator } \\
\text { protein } 1\end{array}$ & 131.4 & 5 & 3.1 & 30.9 & +1.56 \\
\hline Q9BZZ5 & API5 & Apoptosis inhibitor 5 & 37.5 & 4 & 10.0 & 27.2 & +2.22 \\
\hline Q9UKV3 & ACIN1 & $\begin{array}{l}\text { Apoptotic chromatin } \\
\text { condensation inducer in } \\
\text { the nucleus }\end{array}$ & 122.5 & 3 & 3.8 & 19.9 & -2.24 \\
\hline D6RC06 & HINT1 & $\begin{array}{l}\text { Histidine triad } \\
\text { nucleotide-binding } \\
\text { protein } 1\end{array}$ & 7.3 & 1 & 21.5 & 6.7 & +0.84 \\
\hline \multicolumn{8}{|c|}{ TRANSFORMATION SIGNALING PATHWAY } \\
\hline G3XAM7 & CTNNA1 & Catenin alpha-1 & 92.7 & 6 & 8.8 & 76.4 & -1.01 \\
\hline B4DSW9 & CTNNB1 & Catenin beta-1 & 77.5 & 3 & 3.9 & 24.3 & +0.13 \\
\hline O00499 & BIN1 & $\begin{array}{l}\text { Myc box-dependent- } \\
\text { interacting protein } 1\end{array}$ & 43.2 & 1 & 3.6 & 6.3 & -1.12 \\
\hline
\end{tabular}

${ }^{\#}$ Average ratio between the Cancer and Normal cells are reported and significant values indicated (* $p$ $<0.05)$. 
bioRxiv preprint doi: https://doi.org/10.1101/2020.09.09.290387; this version posted September 10, 2020. The copyright holder for this preprint

(which was not certified by peer review) is the author/funder, who has granted bioRxiv a license to display the preprint in perpetuity. It is made available under aCC-BY-NC-ND 4.0 International license.

23 Table 2: Top PAX8-SOX17 commonly regulated genes.

\begin{tabular}{|l|l|l|l|}
\hline \multicolumn{1}{|c|}{ GOMMONLY UP-REGULATED TARGET GENES } & \multicolumn{1}{c|}{ COMMONLY DOWN-REGULATED TARGET GENES } \\
\hline \multicolumn{1}{|c|}{ Log-fold change } & \multicolumn{1}{c|}{ Gene } & Log-fold change \\
\hline SERPINE1 & 5.54863858 & PYY & -8.0262675 \\
\hline IL11 & 5.27536243 & TMEM101 & -5.7263682 \\
\hline NPPB & 5.18800181 & FGF18 & -5.4123449 \\
\hline KLK5 & 4.50271261 & TGM7 & -4.9926057 \\
\hline FGF1 & 4.4055198 & CA2 & -4.8188457 \\
\hline CPA4 & 4.32537639 & CCNA1 & -4.5055642 \\
\hline MYL7 & 3.80515773 & CXCL5 & -4.409147 \\
\hline ADAMTSL4 & 3.79017684 & FOXQ1 & -4.3460707 \\
\hline FILIP1L & 3.64159103 & NOTUM & -4.3070766 \\
\hline HBEGF & 3.62339664 & GBP5 & -4.2098481 \\
\hline TGFBI & 3.61350996 & TMEM171 & -4.1579087 \\
\hline RASD2 & 3.52832382 & ZBED6CL & -4.0422849 \\
\hline PMEPA1 & 3.48254273 & BMPER & -3.7191215 \\
\hline SEMA3C & 3.43402726 & FST & -3.4878197 \\
\hline DYSF & 3.32114739 & ATP2B2 & -3.4437388 \\
\hline ITGA2 & 3.314082 & LRRC61 & -3.441764 \\
\hline CYP1B1 & 3.28587766 & RHOC & -3.4246182 \\
\hline NCF2 & 3.26470577 & MYB & -3.4111303 \\
\hline ABCC3 & 3.21212074 & NMU & -3.4026155 \\
\hline DAB2 & 3.18763588 & PRRX2 & -3.3958186 \\
\hline CA9 & 3.17582117 & TXK & -3.3917272 \\
\hline CD274 & 3.17245293 & AGMAT & -3.3704743 \\
\hline CSF1R & 3.16372011 & CTTNBP2 & -3.3622138 \\
\hline AKR1B10 & 3.09123637 & IQGAP2 & -3.300818 \\
\hline SULT2B1 & 3.077257 & KLHL14 & -3.2936874 \\
\hline PDCD1LG2 & 3.06482259 & LRRC41 & -3.290006 \\
\hline PCP4L1 & 3.05895596 & IMPDH1 & -3.285422 \\
\hline
\end{tabular}

\# Top significant gene expression changes p-values $<0.01$. 
50 Table 3: PAX8-SOX17 significantly co-regulated target proteins

\begin{tabular}{|c|c|c|c|c|c|}
\hline \multicolumn{3}{|c|}{ UP-REGULATED TARGET PROTEINS } & \multicolumn{3}{|c|}{ DOWN-REGULATED TARGET PROTEINS } \\
\hline Protein & Difference & t-ratio & Protein & Difference & t-ratio \\
\hline SERPINE1 & 6.772 & 74.24 & SOX17 & -1.563 & 17.13 \\
\hline Axl & 0.8736 & 9.577 & Cyclin-B1 & -1.211 & 13.27 \\
\hline Gys_pS641 & 0.8122 & 8.903 & RPA32_pS4_pS8 & -1.069 & 11.71 \\
\hline Hif-1-alpha & 0.7834 & 8.589 & Chk1 & -0.9642 & 10.57 \\
\hline VEGFR-2 & 0.7769 & 8.517 & CDK1_pT14 & -0.9087 & 9.961 \\
\hline YAP_pS127 & 0.7397 & 8.109 & DNMT1 & -0.9073 & 9.946 \\
\hline GSK-3a-b_pS21_pS9 & 0.7283 & 7.984 & PAX8 & -0.8738 & 9.579 \\
\hline ATR & 0.7 & 7.674 & DAPK1_pS308 & -0.8424 & 9.235 \\
\hline Connexin-43 & 0.6899 & 7.563 & EMA & -0.8236 & 9.029 \\
\hline HSP27_pS82 & 0.6696 & 7.34 & $\mathrm{MSH} 2$ & -0.7811 & 8.563 \\
\hline $\mathrm{B} 7-\mathrm{H} 4$ & 0.6279 & 6.884 & IDO & -0.766 & 8.398 \\
\hline GSK-3B & 0.6189 & 6.785 & Rb_pS807_pS811 & -0.7593 & 8.323 \\
\hline NDRG1_pT346 & 0.6089 & 6.676 & ATP5A & -0.7315 & 8.019 \\
\hline MLKL & 0.573 & 6.281 & ENY2 & -0.7228 & 7.924 \\
\hline G6PD & 0.5712 & 6.262 & Rheb & -0.7226 & 7.921 \\
\hline p21 & 0.5468 & 5.995 & PARP & -0.7224 & 7.919 \\
\hline Atg7 & 0.5453 & 5.978 & Ets-1 & -0.6919 & 7.585 \\
\hline MCT4 & 0.538 & 5.898 & MSH6 & -0.6902 & 7.566 \\
\hline Stat3 & 0.5376 & 5.894 & Slfn11 & -0.6349 & 6.96 \\
\hline HMHA1 & 0.515 & 5.646 & RBM15 & -0.6324 & 6.933 \\
\hline PEA-15 & 0.5141 & 5.636 & PLK1 & -0.615 & 6.743 \\
\hline Rab25 & 0.5075 & 5.563 & BRD4 & -0.5906 & 6.474 \\
\hline Src_pY416 & 0.5015 & 5.498 & cdc25C & -0.5894 & 6.461 \\
\hline A-Raf & 0.4957 & 5.435 & Cdc6 & -0.575 & 6.303 \\
\hline INPP4b & 0.4906 & 5.378 & FOXM1 & -0.5734 & 6.286 \\
\hline E-Cadherin & 0.4877 & 5.346 & p53 & -0.5685 & 6.233 \\
\hline Gys & 0.4875 & 5.344 & Chk2 & -0.5643 & 6.186 \\
\hline SHP-2_pY542 & 0.4854 & 5.321 & UQCRC2 & -0.5319 & 5.831 \\
\hline Merlin & 0.4832 & 5.297 & AMPKa_pT172 & -0.5024 & 5.508 \\
\hline TRIM25 & 0.4789 & 5.25 & Rad50 & -0.4901 & 5.372 \\
\hline Coup-TFII & 0.4624 & 5.069 & GATA3 & -0.4884 & 5.354 \\
\hline Paxillin & 0.4544 & 4.981 & PYGM & -0.474 & 5.196 \\
\hline NQO1 & 0.4418 & 4.843 & KAP1 & -0.4675 & 5.126 \\
\hline S6_pS235_pS236 & 0.4356 & 4.775 & eEF2 & -0.4655 & 5.103 \\
\hline Mitofusin-2 & 0.4326 & 4.742 & c-Abl_pY412 & -0.4479 & 4.91 \\
\hline Atg5 & 0.4267 & 4.678 & Aurora-A & -0.4457 & 4.886 \\
\hline
\end{tabular}




\section{REFERENCES}

1. Siegel RL, Miller KD, and Jemal A. Cancer statistics, 2019. CA Cancer J Clin. 2019;69(1):7-34.

2. Ferlay J, Colombet M, Soerjomataram I, Mathers C, Parkin DM, Pineros M, et al. Estimating the global cancer incidence and mortality in 2018: GLOBOCAN sources and methods. Int J Cancer. 2019;144(8):1941-53.

3. Reid BM, Permuth JB, and Sellers TA. Epidemiology of ovarian cancer: a review. Cancer Biol Med. 2017;14(1):9-32.

4. Torre LA, Trabert B, DeSantis CE, Miller KD, Samimi G, Runowicz CD, et al. Ovarian cancer statistics, 2018. CA Cancer J Clin. 2018;68(4):284-96.

5. Perets R, and Drapkin R. It's Totally Tubular....Riding The New Wave of Ovarian Cancer Research. Cancer Res. 2016;76(1):10-7.

6. Ducie J, Dao F, Considine M, Olvera N, Shaw PA, Kurman RJ, et al. Molecular analysis of highgrade serous ovarian carcinoma with and without associated serous tubal intra-epithelial carcinoma. Nat Commun. 2017;8(1):990.

7. Labidi-Galy SI, Papp E, Hallberg D, Niknafs N, Adleff V, Noe M, et al. High grade serous ovarian carcinomas originate in the fallopian tube. Nat Commun. 2017;8(1):1093.

8. Wu RC, Wang P, Lin SF, Zhang M, Song Q, Chu T, et al. Genomic landscape and evolutionary trajectories of ovarian cancer precursor lesions. J Pathol. 2019;248(1):41-50.

9. Eckert MA, Pan S, Hernandez KM, Loth RM, Andrade J, Volchenboum SL, et al. Genomics of Ovarian Cancer Progression Reveals Diverse Metastatic Trajectories Including Intraepithelial Metastasis to the Fallopian Tube. Cancer Discov. 2016;6(12):1342-51.

10. Sherman-Baust CA, Kuhn E, Valle BL, Shih le M, Kurman RJ, Wang TL, et al. A genetically engineered ovarian cancer mouse model based on fallopian tube transformation mimics human high-grade serous carcinoma development. J Pathol. 2014;233(3):228-37. 
88 11. McCool KW, Freeman ZT, Zhai Y, Wu R, Hu K, Liu CJ, et al. Murine Oviductal High-Grade

Serous Carcinomas Mirror the Genomic Alterations, Gene Expression Profiles, and Immune Microenvironment of Their Human Counterparts. Cancer Res. 2020;80(4):877-89.

12. Kim J, Coffey DM, Creighton CJ, Yu Z, Hawkins SM, and Matzuk MM. High-grade serous ovarian cancer arises from fallopian tube in a mouse model. Proc Natl Acad Sci $U$ S A. 2012;109(10):3921-6.

13. Stuckelberger S, and Drapkin R. Precious GEMMs: emergence of faithful models for ovarian cancer research. J Pathol. 2018;245(2):129-31.

14. Mittag J, Winterhager E, Bauer K, and Grummer R. Congenital hypothyroid female pax8deficient mice are infertile despite thyroid hormone replacement therapy. Endocrinology. $2007 ; 148(2): 719-25$.

15. Mayran A, Pelletier A, and Drouin J. Pax factors in transcription and epigenetic remodelling. Semin Cell Dev Biol. 2015;44:135-44.

16. Laury AR, Perets R, Piao H, Krane JF, Barletta JA, French C, et al. A comprehensive analysis of PAX8 expression in human epithelial tumors. Am J Surg Pathol. 2011;35(6):816-26.

17. Perets R, Wyant GA, Muto KW, Bijron JG, Poole BB, Chin KT, et al. Transformation of the fallopian tube secretory epithelium leads to high-grade serous ovarian cancer in Brca;Tp53;Pten models. Cancer Cell. 2013;24(6):751-65.

18. Maniati E, Berlato C, Gopinathan G, Heath O, Kotantaki P, Lakhani A, et al. Mouse Ovarian Cancer Models Recapitulate the Human Tumor Microenvironment and Patient Response to Treatment. Cell Rep. 2020;30(2):525-40 e7.

19. Di Palma T, Filippone MG, Pierantoni GM, Fusco A, Soddu S, and Zannini M. Pax8 has a critical role in epithelial cell survival and proliferation. Cell Death Dis. 2013;4:e729. 
11 20. Ghannam-Shahbari D, Jacob E, Kakun RR, Wasserman T, Korsensky L, Sternfeld O, et al. PAX8 activates a p53-p21-dependent pro-proliferative effect in high grade serous ovarian carcinoma. Oncogene. 2018;37(17):2213-24.

21. Rodgers LH, E Oh, Young AN, and Burdette JE. Loss of PAX8 in high-grade serous ovarian cancer reduces cell survival despite unique modes of action in the fallopian tube and ovarian

22. Elias KM, Emori MM, Westerling $\mathrm{T}$, Long $\mathrm{H}$, Budina-Kolomets $\mathrm{A}$, Li $\mathrm{F}$, et al. Epigenetic remodeling regulates transcriptional changes between ovarian cancer and benign precursors. JCI Insight. 2016;1(13).

23. Corona RI, Seo JH, Lin X, Hazelett DJ, Reddy J, Fonseca MAS, et al. Non-coding somatic mutations converge on the PAX8 pathway in ovarian cancer. Nat Commun. 2020;11(1):2020.

24. Garcia-Heredia JM, Verdugo Sivianes EM, Lucena-Cacace A, Molina-Pinelo S, and Carnero A. Numb-like (NumbL) downregulation increases tumorigenicity, cancer stem cell-like properties and resistance to chemotherapy. Oncotarget. 2016;7(39):63611-28.

25. Allen HF, Wade PA, and Kutateladze TG. The NuRD architecture. Cell Mol Life Sci. 2013;70(19):3513-24.

26. Bohm M, Wachtel M, Marques JG, Streiff N, Laubscher D, Nanni P, et al. Helicase CHD4 is an epigenetic coregulator of PAX3-FOXO1 in alveolar rhabdomyosarcoma. J Clin Invest. 2016;126(11):4237-49.

27. Grimley E, Liao C, Ranghini EJ, Nikolovska-Coleska Z, and Dressler GR. Inhibition of Pax2 Transcription Activation with a Small Molecule that Targets the DNA Binding Domain. ACS Chem Biol. 2017;12(3):724-34.

28. De Palma M, Biziato D, and Petrova TV. Microenvironmental regulation of tumour angiogenesis. Nat Rev Cancer. 2017;17(8):457-74. 
29. Zhou H, Yang YH, and Basile JR. Characterization of the Effects of Semaphorin 4D Signaling on Angiogenesis. Methods Mol Biol. 2017;1493:429-41.

30. Zhou H, Yang YH, Binmadi NO, Proia P, and Basile JR. The hypoxia-inducible factor-responsive proteins semaphorin 4D and vascular endothelial growth factor promote tumor growth and angiogenesis in oral squamous cell carcinoma. Exp Cell Res. 2012;318(14):1685-98.

31. Shi K, Yin X, Cai MC, Yan Y, Jia C, Ma P, et al. PAX8 regulon in human ovarian cancer links lineage dependency with epigenetic vulnerability to HDAC inhibitors. Elife. 2019;8.

32. Grimm D, Bauer J, Wise P, Kruger M, Simonsen U, Wehland M, et al. The role of SOX family members in solid tumours and metastasis. Semin Cancer Biol. 2019.

33. Hou L, Srivastava Y, and Jauch R. Molecular basis for the genome engagement by Sox proteins. Semin Cell Dev Biol. 2017;63:2-12.

34. Wilson M, and Koopman P. Matching SOX: partner proteins and co-factors of the SOX family of transcriptional regulators. Curr Opin Genet Dev. 2002;12(4):441-6.

35. Lang D, and Epstein JA. Sox10 and Pax3 physically interact to mediate activation of a conserved c-RET enhancer. Hum Mol Genet. 2003;12(8):937-45.

36. Mascarenhas JB, Littlejohn EL, Wolsky RJ, Young KP, Nelson M, Salgia R, et al. PAX3 and SOX10 activate MET receptor expression in melanoma. Pigment Cell Melanoma Res. 2010;23(2):225-37.

37. Zhang S, Bell E, Zhi H, Brown S, Imran SAM, Azuara V, et al. OCT4 and PAX6 determine the dual function of SOX2 in human ESCs as a key pluripotent or neural factor. Stem Cell Res Ther. 2019;10(1):122.

38. Ooki A, Dinalankara W, Marchionni L, Tsay JJ, Goparaju C, Maleki Z, et al. Epigenetically regulated PAX6 drives cancer cells toward a stem-like state via GLI-SOX2 signaling axis in lung adenocarcinoma. Oncogene. 2018;37(45):5967-81. 
59 39. Reddy J, Fonseca MAS, Corona RI, Nameki R, Dezem FS, Klein IA, et al. Predicting master transcription factors from pan-cancer expression data. bioRxiv 839142. 2019.

40. Yang H, Lee S, Lee S, Kim K, Yang Y, Kim JH, et al. Sox17 promotes tumor angiogenesis and destabilizes tumor vessels in mice. J Clin Invest. 2013;123(1):418-31.

41. Lee SH, Lee S, Yang H, Song S, Kim K, Saunders TL, et al. Notch pathway targets

42. Ramasamy SK, Kusumbe AP, Wang L, and Adams RH. Endothelial Notch activity promotes

43. Pitulescu ME, Schmidt I, Giaimo BD, Antoine T, Berkenfeld F, Ferrante F, et al. DII4 and Notch signalling couples sprouting angiogenesis and artery formation. Nat Cell Biol. 2017;19(8):91527.

44. Kerbel RS. Tumor angiogenesis: past, present and the near future. Carcinogenesis. 2000;21(3):505-15.

45. Kerbel RS. Tumor angiogenesis. N Engl J Med. 2008;358(19):2039-49.

46. Saharinen P, Eklund L, Pulkki K, Bono P, and Alitalo K. VEGF and angiopoietin signaling in tumor angiogenesis and metastasis. Trends Mol Med. 2011;17(7):347-62.

47. Jain RK. Antiangiogenesis strategies revisited: from starving tumors to alleviating hypoxia. Cancer Cell. 2014;26(5):605-22.

48. Jang K, Kim M, Gilbert CA, Simpkins F, Ince TA, and Slingerland JM. VEGFA activates an epigenetic pathway upregulating ovarian cancer-initiating cells. EMBO Mol Med. 2017;9(3):30418.

49. Herr D, Sallmann A, Bekes I, Konrad R, Holzheu I, Kreienberg R, et al. VEGF induces ascites in ovarian cancer patients via increasing peritoneal permeability by downregulation of Claudin 5. Gynecol Oncol. 2012;127(1):210-6. 
83 50. Devy L, Blacher S, Grignet-Debrus C, Bajou K, Masson V, Gerard RD, et al. The pro- or antiangiogenic effect of plasminogen activator inhibitor 1 is dose dependent. FASEB J. $2002 ; 16(2): 147-54$.

51. Stefansson S, Petitclerc E, Wong MK, McMahon GA, Brooks PC, and Lawrence DA. Inhibition of angiogenesis in vivo by plasminogen activator inhibitor-1. J Biol Chem. 2001;276(11):813541.

52. Stefansson S, and Lawrence DA. The serpin PAl-1 inhibits cell migration by blocking integrin alpha V beta 3 binding to vitronectin. Nature. 1996;383(6599):441-3.

53. Wu J, Strawn TL, Luo M, Wang L, Li R, Ren M, et al. Plasminogen activator inhibitor-1 inhibits angiogenic signaling by uncoupling vascular endothelial growth factor receptor-2-alphaVbeta3 integrin cross talk. Arterioscler Thromb Vasc Biol. 2015;35(1):111-20.

54. Vargesson N. Thalidomide-induced teratogenesis: history and mechanisms. Birth Defects Res C Embryo Today. 2015;105(2):140-56.

55. Cortez AJ, Tudrej P, Kujawa KA, and Lisowska KM. Advances in ovarian cancer therapy. Cancer Chemother Pharmacol. 2018;81(1):17-38.

56. Karst AM, and Drapkin R. Primary culture and immortalization of human fallopian tube secretory epithelial cells. Nat Protoc. 2012;7(9):1755-64.

57. Sen P, Lan Y, Li CY, Sidoli S, Donahue G, Dou Z, et al. Histone Acetyltransferase p300 Induces De Novo Super-Enhancers to Drive Cellular Senescence. Mol Cell. 2019;73(4):684-98 e8.

58. Cox J, and Mann M. MaxQuant enables high peptide identification rates, individualized p.p.b.range mass accuracies and proteome-wide protein quantification. Nat Biotechnol. 2008;26(12):1367-72.

59. Doberstein K, Spivak R, Feng Y, Stuckelberger S, Mills GB, Devins KM, et al. Fallopian tube precursor lesions of serous ovarian carcinoma require L1CAM for dissemination and metastasis. bioRxiv 2018;270785. 
08 60. Zhou Y, Zhou B, Pache L, Chang M, Khodabakhshi AH, Tanaseichuk O, et al. Metascape provides a biologist-oriented resource for the analysis of systems-level datasets. Nat Commun. 2019;10(1):1523.

11 61. Strub T, Ghiraldini FG, Carcamo S, Li M, Wroblewska A, Singh R, et al. SIRT6 haploinsufficiency induces BRAF(V600E) melanoma cell resistance to MAPK inhibitors via IGF signalling. Nat Commun. 2018;9(1):3440.

62. Bader DA, Hartig SM, Putluri V, Foley C, Hamilton MP, Smith EA, et al. Mitochondrial pyruvate import is a metabolic vulnerability in androgen receptor-driven prostate cancer. Nat Metab. 2019;1(1):70-85.

63. Grote T, Siwak DR, Fritsche HA, Joy C, Mills GB, Simeone D, et al. Validation of reverse phase protein array for practical screening of potential biomarkers in serum and plasma: accurate detection of CA19-9 levels in pancreatic cancer. Proteomics. 2008;8(15):3051-60.

64. Kimbrel EA, Davis TN, Bradner JE, and Kung AL. In vivo pharmacodynamic imaging of proteasome inhibition. Mol Imaging. 2009;8(3):140-7. 